\title{
Licenciamento ambiental de grandes empreendimentos: quais os limites para avaliação de impactos diretos e indiretos em saúde? Estudo de caso na Terra Indígena Wajãpi, Amapá Environmental licensing of large-scale enterprises: what are the limits for evaluating direct and indirect impacts on health? A case study in the Wajãpi Indigenous Land, Amapá
}

\author{
Eduardo Stramandinoli Moreno', Joana Cabral Oliveira"l, Paloma Helena Fernandes Shimabukuro'II, Luciana Carvalho \\ Universidade Federal do Oeste do Pará. Santarém, Pará, Brasil \\ "Universidade Estadual de Campinas. Campinas, São Paulo, Brasil \\ IIIInstituto René Rachou. Belo Horizonte, Minas Gerais, Brasil
}

\begin{abstract}
Resumo: A realização de estudos de impacto ambiental (EIA) prévios à implantação de grandes empreendimentos é obrigatória no Brasil. Porém, os critérios normativos para delimitação de áreas de influência são considerados imprecisos e insuficientes. $\bigcirc$ presente artigo busca demonstrar como impactos ambientais em série causados pela implantação de usinas hidrelétricas e por projetos de mineração industrial no Amapá desencadearam surtos de malária e de leishmaniose tegumentar americana (LTA) na Terra Indígena Wajãpi e em outros assentamentos da região central do estado. Análises espaciais de desmatamento, curvas de variações climáticas e cronologia de impactos de tais empreendimentos, feitas entre 2003 e 2015, foram utilizadas para verificar a correlação de efeitos na saúde em comunidades não incluídas durante as diversas fases do licenciamento para implantação destes empreendimentos. Os resultados demonstram que surtos de malária e de LTA estiveram correlacionados com aumento das taxas de desmatamento causado pela expansão de assentamentos rurais, mas principalmente pela implantação de duas usinas hidrelétricas e intensificação de atividades de mineração industrial de ouro e de ferro, assim como o consequente incremento de garimpos na região. Os resultados explicitam a fragilidade do processo de licenciamento ambiental para delimitação de áreas de influência indireta, principalmente relacionados a aspectos da saúde.
\end{abstract}

Palavras-chave: Licenciamento ambiental. Usinas hidrelétricas. Mineração. Doenças transmitidas por vetores. Saúde ambiental.

\begin{abstract}
In Brazil, it is mandatory to conduct environmental impact studies prior to deploying large-scale ventures. However, the normative criteria for demarcating areas of influence are considered imprecise and insufficient. The present article aims to demonstrate how serial environmental impacts caused by the implementation of hydroelectric power plants and industrial mining in the state of Amapá triggered outbreaks of malaria and American cutaneous leishmaniasis (ACL) in the Wajãpi Indigenous Land and other settlements in the region. Spatial analysis of deforestation, climate variation curves, and the chronology of events from 2003 to 2015 were used to verify the correlation of indirect health effects in communities wich were not included during the licensing stages for deploying these projects. The results showed that outbreaks of malaria and $\mathrm{ACL}$ were correlated with increased rates of deforestation caused by the expansion of rural settlements, but mainly by the establishment of two hydroelectric power plants, the growth in industrial iron mining, as well as the simultaneous increase of mining camps (garimpos) in the region. The results highlight the fragility of the environmental licensing process for demarcating indirectly influenced areas, particularly with regard to health issues.
\end{abstract}

Keywords: Environmental licensing. Hydroelectric power plants. Mining. Vector-borne-diseases. Environmental health.

\footnotetext{
MORENO, Eduardo Stramandinoli; OLIVEIRA, Joana Cabral; SHIMABUKURO, Paloma Helena Fernandes; CARVALHO, Luciana. Licenciamento ambiental de grandes empreendimentos: quais os limites para avaliação de impactos diretos e indiretos em saúde? Estudo de caso na Terra Indígena Wajãpi, Amapá. Boletim do Museu Paraense Emílio Goeldi. Ciências Humanas, v. 13, n. 3, p. 519-540, set.dez. 2018. DOI: http://dx.doi.org/10.1590/1981.81222018000300003.

Autor para correspondência: Eduardo Stramandinoli Moreno. Universidade Federal do Oeste do Pará. Rua Vera Paz, s/n (Unidade Tapajós) - Salé. Santarém, PA, Brasil. CEP 68035-110 (eduardo_smoreno@yahoo.com.br).ORCID: http://orcid.org/0000-0003-1544-7115.
}

Recebido em 18/01/2018

Aprovado em 27/06/2018
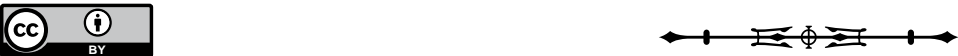


\section{INTRODUÇÃO}

Em meio a uma enorme crise política e econômica, em agosto de 2017, o governo federal publicou o Decreto $n$. 9.142/2017, que extingue a Reserva Nacional do Cobre e Associados (RENCA), a fim de atrair investimentos privados para o setor de mineração (Brasil, 2017a). A área de aproximadamente quatro milhões de hectares, localizada na divisa entre o sul e o sudoeste do Amapá com o Pará, foi criada em 1984, sob a égide do regime militar, para preservar os recursos minerais'. Rica em ouro, ferro, manganês e tântalo, a RENCA sobrepõe-se parcialmente às áreas de proteção ambiental e a terras indígenas (Wajãpi, Paru d'Oeste e Parque do Tumucumaque). Segundo o governo, a sua extinção permitiria a concessão para exploração e aproveitamento do potencial mineral da região, estimulando o desenvolvimento econômico nacional. Alegou-se, ainda, que a regulamentação da atividade minerária coibiria garimpos ilegais já existentes no local, os quais aumentariam frente ao alarde sobre a existência da reserva; argumento semelhante ao que fora usado na década de 1990 para legalizar garimpos em terras yanomami (Ramos, 1993).

Após repercussões negativas e grande mobilização de grupos ambientalistas, de órgãos indigenistas e da opinião pública nacional e internacional, com atuação dos Wajãpi na linha de frente desses manifestos, com voz pungente contra a extinção da RENCA ${ }^{2}$, o governo federal revogou o referido decreto por meio de outro (Decreto n. 9.147/2017) (Brasil, 2017b). Em setembro, por fim, o governo publicou o Decreto n. 9.159/2017, que suspendeu os efeitos da abertura da reserva e revigorou aqueles relativos à sua criação (Brasil, 2017c).
Assim, foram cancelados os planos de permissão para extração mineral, determinando-se que qualquer nova alteração só seria levada a cabo após uma discussão adequada com a sociedade.

Apesar de a repercussão negativa ter provocado a reavaliação da resolução inicial, a ameaça de liberação da RENCA mantém-se eminente e viva. $O$ processo autoritário de decisão de sucessivos governos sobre a exploração de recursos naturais renováveis e não renováveis é bastante comum em diversas regiões da Amazônia, gerando significativos impactos socioambientais e sanitários, com variada visibilidade. Conforme afirmam Fearnside e Laurence (2012, p. 91), quando projetos desenvolvimentistas repercutem de maneira negativa na imprensa e na sociedade, causando ônus político, "[...] eles podem simplesmente ficar latentes durante décadas para reemergirem depois, em um momento mais politicamente favorável".

A pressão pela abertura de áreas protegidas e de terras indígenas na Amazônia para a exploração mineral não é recente e ocorre em diferentes esferas de ação política (Capiberibe; Bonilla, 2015, 2012). Em um diagnóstico do setor mineral do Amapá, publicado pelo governo desse estado (Oliveira, M., 2010), são apontados entraves para um suposto desenvolvimento, entre eles: (i) a ocorrência de 20\% da província metalogenética em terras indígenas, onde, no momento, a mineração está impedida; (ii) a existência da RENCA, que impede a exploração em área que apresenta potencialidade mineral; (iii) a sobreposição de cerca de 70\% da RENCA a unidades de conservação (UC), o que limita ainda mais o acesso às commodities minerais ${ }^{3}$. Diante desses supostos obstáculos, as ações propostas pelo documento são: (a) articulação política do estado para pressionar o

A RENCA foi criada pelo Decreto n. 89.404/1984 (Brasil, 1984) e alterada pelo Decreto n. 92.107/1985 (Brasil, 1985).

2 Vídeos e reportagens em que os Wajãpi aparecem como um dos grupos ameaçados pelo empreendimento foram produzidos por diferentes e relevantes fontes nacionais e internacionais, entre as quais: El País, The Guardian, The New York Times, Veja, Folha de São Paulo, Estadão, TV Globo e portais da internet. A ampla divulgação de matérias sobre o caso fomentou um debate acalorado nas redes sociais e alimentou petições contrárias ao decreto.

3 Apesar de fortes pressões em sentido contrário e do propósito expresso do Departamento Nacional de Pesquisa Mineral (DNPM) de articular novas regras com os órgãos ambientais, a legislação brasileira em vigor proíbe, de modo geral, atividades de mineração em unidades de conservação, havendo exceções a depender da data de criação da UC. Para uma discussão sobre o assunto, ver Lima (2006).

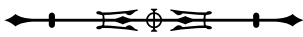


legislativo federal a regulamentar matéria que trata da mineração em terra indígena; (b) "[...] articulação política para a revogação do decreto que criou a RENCA" (Oliveira, M., 2010, p. 134); (c) inclusão da atividade mineral no plano de manejo das unidades de conservação de uso sustentado que têm sobreposição com a RENCA (Oliveira, M., 2010).

Experiências de exploração minerária em unidades de proteção - apoiadas na intrincada legislação que regula direitos ao solo e ao sub-solo, e confunde interesse nacional com interesse público (Lima, 2006) - têm respondido por inúmeros conflitos socioambientais. No estado do Pará, são emblemáticos os casos da Floresta Nacional de Carajás (Martins; Mendonça, 2014) e de Saracá-Taquera (Wanderley, 2008). Em se tratando de UC de uso sustentável que são ocupadas por povos e comunidades tradicionais que sofrem com os impactos socioambientais provenientes da mineração, o interesse público nessas áreas é notoriamente controverso. Com o aval do governo, o suposto 'público' sobrepuja o interesse das comunidades locais.

Não bastassem os imbróglios causados por uma legislação caracterizada por "[...] lacunas, sobreposições, imprecisões e controvérsias [que podem] levar a uma deliberada confusão nas decisões políticas e jurídicas a respeito do uso do subsolo nas UC" (Lima, 2006, p. 9), os processos de licenciamento ambiental que antecedem a instalação de tais empreendimentos tendem a apresentar falhas graves, comprometendo o direito constitucional ao meio ambiente ecologicamente equilibrado. Não se trata de uma característica exclusiva dos procedimentos para a instalação de empreendimentos em unidades de conservação, mas de um traço recorrente nos processos de licenciamento ambiental no Brasil, como demonstra a coletânea de artigos organizada sob o sugestivo título "A insustentável leveza da política ambiental: desenvolvimento e conflitos socioambientais" (Zhouri et al., 2005).

Os impactos ambientais causados por grandes empreendimentos - como contrução de usinas hidrelétricas, atividades de mineração e de agronegócio - são severos em muitas formas, e vão além de transformações diretas e imediatas de uso do território. Se alguns tipos de impactos diretos, como desmatamentos ou alagamentos, são considerados de modo instantâneo, os indiretos envolvendo questões de saúde são ainda bastante limitados ou quase inexistentes nas avaliações.

Muitas e variadas são as possíveis interferências decorrentes do processo de instalação dos grandes empreendimentos, entre as quais pode-se destacar como as mais comuns: (i) necessidade de realocação de comunidades, ação que gera uma brusca alteração de seus modos de existência; (ii) grande migração populacional, que traz consigo violência, aumento da criminalidade, prostituição e consequente aumento das doenças sexualmente transmissíveis; (iii) desmatamento ou alagamento de grandes áreas, gerando intenso desequilíbrio ecológico, o que afeta a disponibilidade de caça e de pesca, que ocasiona a redução de áreas cultiváveis e a proliferação da população de vetores, incluindo artrópodos e moluscos, levando ao aumento na incidência de malária e de outras doenças.

Em relação a este último padrão de impacto, a usina hidrelétrica de Tucuruí, no Pará, talvez seja até hoje o exemplo mais claro sobre o qual o aumento da densidade de vetores e da incidência da malária foi mais bem documentado (Vasconcelos et al., 2006; Couto et al., 2001). Entre os exemplos nos quais se pode identificar tal correlação, pode-se citar os casos das usinas de Santo Antônio e de Jirau, em Rondônia (Katsuragawa et al., 2009), de Balbina, no Amazonas (Quintero et al., 1996), de Itaipu, no Paraná (Bértoli; Moitinho, 2001), entre outros casos (Rezende et al., 2009; Koifman, 2001). Uma revisão de dados da Fundação Nacional do Índio (FUNAI) sobre os impactos de usinas hidrelétricas em mais de 150 terras indígenas no Brasil demonstra que os efeitos afetam direta ou potencialmente mais de um terço da população indígena brasileira, evidenciando o racismo ambiental que permeia a vida destas populações (Koifman, 2001; Porto et al., 2013). A proliferação de doenças transmitidas por vetores 
consta entre os principais impactos citados (Koifman, 2001). São abundantes os exemplos de como a implantação de atividades de mineração possibilita a proliferação de insetos vetores e a incidência de doenças como malária e leishmaniose (Andrade et al., 1995; Duarte; Fontes, 2002; Chagas et al., 2006; Barbieri; Sawyer, 2007).

Ramos (1993), em seu estudo pioneiro intitulado "O papel político das epidemias: o caso Yanomami”, descreve o crescente efeito das políticas expansionistas de garimpo e de mineração sobre a malária entre os Yanomami, em Roraima. Posteriormente, diversos outros trabalhos explicitam como comunidades indígenas são especialmente vulneráveis à convivência com grandes empreendimentos (Rigotto, 2009). Por outro viés, lideranças indígenas têm dado acesso a perspectivas internas sobre como lidam e percebem a imposição de atividades minerárias em seus territórios. Kopenawa e Albert (2015) e Albert (2002) mostram como os Yanomami atrelam, de modo direto, a extração do ouro às epidemias que ameaçam não só a existência de seu povo, mas apontam para a possibilidade de um colapso da terra. $\bigcirc$ xamanismo está entre as ferramentas agenciadas para lidar com as catástrofes advindas da exploração desmedida dos brancos. Contudo, a compreensão e a agência indígenas são mais um quesito normalmente ignorado pelos estudos de impacto.

De acordo com dados do I Inquérito Nacional de Saúde e Nutrição dos Povos Indígenas (Cardoso et al., 2009), há forte correlação entre contextos socioambientais injustos, processos históricos de expropriação, discriminação, condições adversas de vida e desestruturação dos modos de existência de comunidades indígenas. Combinados, tais fatores levam a cenários nos quais esses povos vivem em situações de maior vulnerabilidade e desvantagem em relação a outros segmentos da população nacional, mesmo quando comparados com as frações mais pobres da sociedade brasileira (Porto et al., 2013). O relatório final do inquérito aponta, por exemplo, que transformações sociais, culturais, ambientais e econômicas contribuem significativamente para que problemas de saúde característicos da pobreza e da vulnerabilidade social como as doenças infecto-parasitárias (principalmente a malária), a anemia e a desnutrição - permaneçam como questões importantes para se pensar no quadro de morbimortalidade entre povos indígenas.

$\bigcirc$ presente artigo pretende contribuir para o debate sobre o modelo de desenvolvimento imputado à Amazônia, considerando especificamente a importância da participação do setor da saúde nos processos de licenciamento ambiental de grandes empreendimentos. Parte-se de um estudo de caso realizado na Terra Indígena Wajãpi (TIW), que discute como a crescente ocorrência de atividades de mineração e a construção de usinas hidrelétricas no Amapá desencadearam um efeito cascata de aumento de doenças transmitidas por vetores (especificamente, malária e LTA) em áreas que não foram consideradas como zonas de impacto dos últimos empreendimentos.

Essas doenças são consideradas endêmicas no estado do Amapá, de forma que são esperados alguns casos anualmente. Porém, o número de casos de ambas as doenças na TIW aumentou abruptamente a partir de 2012, com taxas de incidência proporcionalmente maiores em comparação a municípios e a assentamentos vizinhos. Tal percepção se deu inicialmente pela própria população e por profissionais de saúde atuantes na região, o que desencadeou uma pesquisa multi-institucional, a fim de identificar possíveis determinantes socioambientais neste processo.

Esse cenário levantou questionamentos sobre o aumento de casos das doenças de transmissão vetorial na TIW e, a partir de 2012, delineou o projeto "Determinantes socioambientais da leishmaniose tegumentar americana, na Terra Indígena Wajãpi, Amapá" (Conselho Nacional de Desenvolvimento Científico e Tecnológico - CNPq, processo 404390/2012-9), cujo objetivo era avaliar os principais fatores de risco para a LTA, utilizando-se uma abordagem interdisciplinar. Na oportunidade, atividades de campo permitiram a identificação dos marcos temporais e

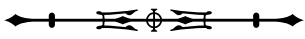


das modificações ambientais e sanitárias percebidas pelos Wajãpi no contexto desta pesquisa (Moreno et al., 2016).

Fatores externos também foram levantados como possíveis determinantes para o processo investigado. Por um lado, a mineração, realizada tanto em pequenos garimpos quanto por grandes empresas instaladas historicamente na região, provoca importantes impactos ambientais nos municípios fronteiriços à TIW. Por outro lado, a partir de 2011, iniciou-se o processo de instalação de duas usinas hidrelétricas (UHE) - Ferreira Gomes e Cachoeira Caldeirão - a cerca de $150 \mathrm{~km}$ dos limites da TIW, impactando a bacia do rio Araguari, da qual muitos rios e igarapés da TIW fazem parte. Contudo, a simultaneidade de tantos possíveis fatores de impactos no já complexo contexto de ocupação territorial da região não permitiu uma visão clara dos motivos de ocorrência dos surtos de doenças de transmissão vetorial na TIW.

Assim, demonstra-se aqui as dificuldades de avaliar os impactos indiretos e cumulativos em contextos nos quais grandes alterações ambientais são estabelecidas em série, bem como a complexidade de mensurar como eles se projetam para além dos perímetros considerados nos estudos de impacto que atendem à legislação de licenciamento ambiental ora vigente. Utiliza-se o 'princípio de consiliência', também conhecido como convergência de evidência ou concordância de evidência, para o qual evidências de fontes independentes e não relacionadas podem 'convergir' para o estabelecimento de fortes conclusões. Ou seja, quando várias fontes de evidência estão de acordo, a conclusão pode ser muito forte, mesmo quando nenhuma das fontes é significativamente forte, ao ser considerada individualmente (Wilson, 1998).

\section{MARCO TEÓRICO}

Estudos técnicos de Avaliação de Impacto Ambiental (AIA) em diferentes escalas fazem parte dos procedimentos preliminares do licenciamento ambiental, obrigatório para instalação de empreendimentos ou de atividades com potencial de poluição ou de degradação do meio ambiente.
A Resolução CONAMA n. 001/86 é o documento de referência que estabelece, no Brasil, as diretrizes gerais para uso e implementação da AIA como um dos instrumentos da Política Nacional do Meio Ambiente (PNMA). Tem como seus principais dispositivos o Estudo de Impacto Ambiental (EIA) e o Relatório de Impacto Ambiental (RIMA).

No art. $1^{\circ}$, a supracitada Resolução define impacto ambiental como:

[...] qualquer alteração das propriedades físicas, químicas e biológicas do meio ambiente, causada por qualquer forma de matéria ou energia resultante das atividades humanas que, direta ou indiretamente, afetam: I - a saúde, a segurança e o bem-estar da população; II - as atividades sociais e econômicas; III - a biota; IV - as condições estéticas e sanitárias do meio ambiente; $\mathrm{V}-\mathrm{a}$ qualidade dos recursos ambientais. (Brasil, 1986).

O conteúdo a ser apresentado no estudo varia de acordo com a atividade pretendida e as especificidades ambientais e sociais da região na qual o projeto se insere (Oliveira, F.; Medeiros, 2007). A propósito, a Resolução CONAMA n. 001/86, art. 5०, inciso III, traz a necessidade de "Definir os limites da área geográfica a ser direta ou indiretamente afetada pelos impactos, denominada área de influência do projeto, considerando, em todos os casos, a bacia hidrográfica na qual se localiza" (Brasil, 1986).

artigo $6^{\circ}$, inciso II, determina que o estudo de impacto ambiental deva desenvolver, no mínimo, as seguintes atividades técnicas:

\begin{abstract}
Análise dos impactos ambientais do projeto e de suas alternativas, através de identificação, previsão da magnitude e interpretação da importância dos prováveis impactos relevantes, discriminando: os impactos positivos e negativos (benéficos e adversos), diretos e indiretos, imediatos e a médio e longo prazos, temporários e permanentes; seu grau de reversibilidade; suas propriedades cumulativas e sinérgicas; a distribuição dos ônus e benefícios sociais. (Brasil, 1986).
\end{abstract}

Apesar de haver indicativos da necessidade de avaliação dos impactos indiretos e cumulativos, eles 
são abordados de forma superficial, sendo considerados por muitos autores como imprecisos e insuficientes (Oliveira, V., 2008). Conforme Bursztyn, Maria e Bursztyn, Marcel (2012, p. 505), "[...] o licenciamento de cada um, isoladamente, permite que possíveis impactos cumulativos ou sinérgicos sejam negligenciados na análise". Segundo Generoso (2012, p. 4):

A necessidade de prévio licenciamento ambiental para implantação e operação de empreendimentos potencialmente geradores de prejuízos ambientais está orientada pelos hoje propagados princípios da prevenção e da precaução.

Antunes (2008, p. 45) complementa que este princípio "[...] aplica-se a impactos ambientais já conhecidos e dos quais se possa, com segurança, estabelecer um conjunto de nexos de causalidade que seja suficiente para a identificação dos impactos futuros mais prováveis".

Historicamente, no Brasil, os planos plurianuais - "[...] conjuntos de investimentos do governo federal brasileiro para períodos de quatro anos" (Fearnside; Laurence, 2012, p. 87) - trazem em comum uma forma de planejamento que prevê grandes obras de expansão programadas para a região amazônica, incluindo implantação de rodovias, atividades de mineração industrial e construção de usinas hidrelétricas. No entanto, o período limitado de quatro anos, previsto para execução de tais obras, traz como efeito a aceleração do processo de licenciamento ambiental, da licitação e do financiamento. Constata-se que

[...] poderosos grupos de interesse, a favor de construção de cada projeto, são mobilizados antes dos impactos ambientais e sociais serem avaliados. Essa avaliação somente acontece pouco antes do começo da construção. [...] Uma vez que o financiamento é mobilizado para um projeto, um lobby com interesses financeiros na aprovação do projeto se forma automaticamente, aumentando, assim, a probabilidade de aprovação governamental, independentemente dos impactos ambientais e sociais que possam ser provocados. (Fearnside; Laurence, 2012, p. 87)
Dessa forma, criam-se contextos e condições que influenciam e tendenciam o EIA e o RIMA, que acabam por se limitar à avaliação de impactos diretos, sendo comum a alienação para com danos indiretos, como aqueles causados pela atração de atividades econômicas por eles facilitadas (Fearnside; Laurence, 2012; Silveira; Araújo Neto, 2014; ISA, 2015). Ignora-se frequentemente o fato de que $\mathrm{o}$ incremento da acessibilidade favorece a instalação de atividades envolvendo grilagem de terras, extração de madeira e garimpos ilegais (Fearnside, 2001).

O processo de licenciamento ambiental é composto por até três etapas que, em caso de aprovação, resultam em três licenças ambientais sucessivas: (i) licença prévia (LP), (ii) licença de instalação (LI) e (iii) licença de operação (LO) (Silveira; Araújo Neto, 2014). A LP corresponde à fase de planejamento do empreendimento, quando são realizados estudos para avaliar sua viabilidade e projetar sua implantação. A LI autoriza a instalação do empreendimento de acordo com o projeto aprovado na fase LP. A LO autoriza a operação do empreendimento.

A rigor, a tomada de decisões a respeito da expedição de licenças no fluxo do processo de licenciamento ambiental deve envolver a participação social. Para tal, o instrumento previsto pela legislação é a audiência pública. Contudo, as leis não são claras quanto à natureza de tais audiências - se devem ser consultivas ou deliberativas -, como se depreende da Resolução CONAMA n. 009/87:

Art. $1^{\circ}$ A Audiência Pública referida na Resolução CONAMA n. 1/86 tem por finalidade expor aos interessados o conteúdo do produto em análise e do seu referido RIMA, dirimindo dúvidas e recolhendo dos presentes as críticas e sugestões a respeito.

Art. $2^{\circ}$ Sempre que julgar necessário, ou quando for solicitado por entidade civil, pelo Ministério Público, ou por 50 (cinquenta) ou mais cidadãos, o Órgão de Meio Ambiente promoverá a realização de audiência pública. (Brasil, 1990)

As audiências públicas são coordenadas pelo órgão ambiental, idealmente destinadas à oitiva da sociedade civil,

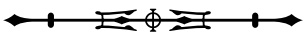


que tem, nesse momento, a oportunidade de se manifestar sobre o licenciamento de um empreendimento, inclusive sugerindo modificações em seu projeto. Entretanto, não são poucos os casos em que elas não satisfazem as necessidades de esclarecimento dos participantes (Zhouri, 2008), correspondendo, antes, à teatralização de um direito, em ocasiões em que "[...] a retórica da participação social tem proporcionado, inclusive, a manutenção de situações de opressão" (Paraíso, 2005, p. 145).

A partir dos estudos de AIA e das colocações apresentadas nas audiências públicas, é possível que o poder público, por intermédio do órgão licenciador, estipule condicionantes a serem cumpridas pelo empreendedor em cada fase, como forma de mitigar ou de compensar impactos decorrentes do empreendimento. Conforme descrito por Generoso (2012, p. 5):

[... ] as licenças ambientais (LP, LI e LO) podem ser expedidas com ou sem condicionantes, ou seja, com ou sem determinados requisitos e obrigações que devem ser adicionalmente observados para que a atividade se desenvolva regularmente. As condicionantes funcionam como requisitos a serem estabelecidos pelo poder público em cada uma das três etapas do licenciamento.

[...] estas condicionantes passam a ser a principal base, e talvez a única, de verificação de conformidade ambiental do empreendimento na fiscalização ou na revisão das licenças ambientais [...] (Brandt; Avelar, [201-] apud Generoso, 2012, p. 5).

Entretanto, em estudo recente sobre os efeitos da UHE de Belo Monte sobre comunidades indígenas, a própria condicionante - que visa a mitigar os danos em cadeia, pautada em compensações financeiras - é entendida pelos supostos beneficiários como nefasta. $\mathrm{Ou}$ seja, o que os órgãos planejadores entendem como uma ação positiva - dado o valor que a economia, os bens e o dinheiro possuem na sociedade nacional - é compreendido e vivido pelos indígenas como um problema que causa impactos sobre as relações sociais e os sistemas de conhecimento. Como nos mostra Heurich (2015, p. 77), a partir da visão Araweté: "As mercadorias do Plano Emergencial, assim, nada mais são que um adiantamento, que no futuro será cobrado com juros. As mercadorias, então, seriam o pagamento antecipado pela morte do povo do Ipixuna".

Processos como esse exemplificam a incongruência do diálogo entre as empresas responsáveis, as comunidades potencialmente afetadas e o poder público durante as fases do licenciamento ambiental. A recorrente dificuldade de diálogo impulsionou, a partir de 2014, a elaboração de protocolos de consulta prévia, previsto pela Convenção n. 169, da Organização Internacional do Trabalho (Convenção..., 2011), de organizações indígenas ${ }^{4}$, com o objetivo de "[...] assegurar no ponto de partida um mínimo de equivalência entre as forças dos interlocutores" (Peruzzo, 2016, p. 2727).

A legislação de licenciamento ambiental de grandes empreendimentos corre ainda o risco de ser modificada pela eventual aprovação da Proposta de Emenda Constitucional (PEC) n. 65/2012, que busca estabelecer a dispensa das três etapas de licenciamento para o empreendedor que apresente o EIA, de forma que a obra não possa mais ser suspensa ou cancelada (Zhouri et al., 2016; Sebben; Da Silva, 2016). Atualmente, a PEC aguarda aprovação junto ao Senado.

Nesse sentido, como apontado por Fearnside e Laurence (2012, p. 90):

Empresas consultoras tendem a preparar relatórios favoráveis à aprovação dos projetos, já que as consultorias são contratadas pelos proponentes da iniciativa em foco, que têm interesses financeiros na sua aprovação. Os EIA/RIMA são custeados pelo proponente, o qual, assim, tem influência na escolha da equipe contratada e na fixação de prazos finais inexequíveis, dando atenção sumária aos problemas causados pelos projetos.

\footnotetext{
4 Neste contexto, os Wajãpi, assim como os Munduruku, foram pioneiros ao criarem e apresentarem seus protocolos específicos para consultas prévias.
}

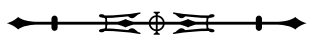


É importante enfatizar que questões relacionadas aos aspectos da saúde tendem a ser negligenciadas durante os processos de licenciamento (Zhouri et al., 2005; Porto et al., 2013; Silveira; Araújo Neto, 2014), os quais nem sempre são evidentes, de forma que, em muitos casos, os benefícios ou prejuízos das modificações introduzidas pelos empreendimentos que licenciam só podem ser visualizados e compreendidos em análises que conectem processos de larga escala às especificidades estruturais, ambientais e populacionais. Assim, há uma carência de indicadores capazes de evidenciar interações entre pressões socioeconômicas e degradação ambiental, e mostrar também como ambas combinadas são capazes de afetar os serviços ambientais que servem de suporte à vida, à saúde e ao bem-estar (Freitas, 2011). A inclusão da avaliação de impacto na saúde nos processos de licenciamento ambiental coloca o campo da saúde como um englobador de uma gama ampla de determinantes e já foi proposta na I Conferência Nacional de Meio Ambiente (2003). Assim, mesmo que o referencial normativo explicite "[...] a importância da participação do setor saúde no planejamento dos projetos de desenvolvimento [...], ainda não há legislação específica que estabeleça participação do setor saúde nos processos de licenciamento ambiental [...]" (Silveira; Araújo Neto, 2014, p. 3833).

Resultados de uma pesquisa realizada pelo Ministério da Saúde, em 2008, demonstraram que, de um total de 36 estudos analisados pelo setor de saúde entre 2004 e 2007 , apenas 18 (50\%) tiveram algum tipo de recomendação de saúde incorporada como condicionante às licenças ambientais emitidas pelo órgão federal (Silveira; Araújo Neto, 2014). Outro fato citado na pesquisa foi de que:

[...] o envolvimento de mais um órgão no processo é visto como um 'entrave ao desenvolvimento', já que a pressão, normalmente exercida pelo empreendedor, para obter as licenças ambientais em tempo hábil, é recorrente durante as avaliações pelo Instituto Brasileiro do Meio Ambiente e dos Recursos Naturais Renováveis (IBAMA). (Silveira; Araújo Neto, 2014, p. 3834-3835)
Demonstra-se, assim, uma tendência à desvalorização das questões de saúde nos processos, de modo que dificilmente são definidas medidas nesse setor como fatores condicionantes para emissão das licenças ambientais ao empreendedor.

A exceção se dá no caso de licenciamentos para projetos de assentamento de reforma agrária e grandes empreendimentos, como a construção de usinas hidrelétricas e a realização de atividades de mineração em regiões endêmicas para malária, de forma que a avaliação do potencial malarígeno é obrigatória (Portaria da Secretaria de Vigilância Sanitária do Ministério da Saúde - SVS/MS n. 47/2006; Resolução CONAMAn. 286/2001) (Brasil, 2007, 2001). Porém, muitas outras doenças de ciclos ambientais, como as leishmanioses, apesar de possuírem importante potencial epidêmico, são menos utilizadas como indicadores sanitários de impactos ambientais e sociais, pela dificuldade de se estabelecer correlações diretas entre causas e efeitos a longo prazo. Isso se dá principalmente pelo período de incubação e pela cronicidade das condições clínicas, assim como por sua complexa rede ambiental de manutenção e de transmissão. Nessas doenças, a interação parasito-hospedeiro é dinâmica e fortemente influenciada por alterações ambientais, tais como desflorestamento, fragmentação e perda de qualidade de habitats - fatores que influenciam a estrutura da comunidade de fauna local de potenciais vetores e hospedeiros (Conceição-Silva; Alves, C., 2014).

\section{MÉTODOS}

\section{ÁREA DE ESTUDO}

O foco deste estudo se deu sobre a rodovia Perimetral Norte (BR-210), no Amapá, em trecho de cerca de 150 km, que conecta os municípios de Ferreira Gomes, Porto Grande, Serra do Navio e Pedra Branca do Amapari. Essa região caracteriza-se por apresentar diferentes tipos de uso da terra: zonas urbanas, oito assentamentos rurais do Instituto Nacional da Colonização e Reforma Agrária

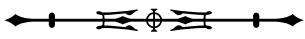


(INCRA), quatro unidades de conservação (Parque Nacional Montanhas do Tumucumaque, Floresta Nacional do Amapá, Reserva do Desenvolvimento Sustentável Rio Iratrapuru e Reserva Particular do Patrimônio Natural Seringal do Triunfo), áreas de mineração industrial, garimpos ilegais, madeireiras, usinas hidrelétricas antigas e recentemente implantadas e a Terra Indígena Wajãpi (TIW).

A TIW estende-se entre as bacias dos rios Jari (a oeste), Amapari (a leste) e Oiapoque (ao norte). Sua demarcação foi homologada em 1996, com uma extensão territorial de 6.070 km² (Gallois et al., 2011). A área é de floresta tropical densa e relevo acidentado, integrando o complexo das montanhas do Tumucumaque. Os Wajãpi que ali vivem, falantes de uma língua do tronco Tupi, organizamse em grupos locais autônomos, que se distribuem de modo disperso pelo território. A população conta com pouco mais de 1.100 pessoas, espalhadas em mais de 80 pequenas aldeias, ocupadas por um pequeno conjunto de famílias nucleares relacionadas por vínculos de parentesco.

\section{MARCOS TEMPORAIS}

Eventos com grande potencial de impacto ambiental e sanitário foram listados a partir de uma extensa revisão bibliográfica com foco sobre o histórico da região e a implantação de garimpos, de mineração industrial e de usinas hidrelétricas, no período compreendido entre os anos de 2003 e 2015. Buscou-se identificar em documentos oficiais, reportagens, teses acadêmicas e artigos científicos momentos de início de atividades de cada um desses empreendimentos, os processos de obtenção de licenças e possíveis problemas relacionados a compensações ambientais e sociais, identificados no contexto. Tais variáveis foram utilizadas como possíveis marcos temporais potencialmente relacionados às curvas de casos de LTA e malária na região de estudo.

Dados do Ministério da Saúde, do Sistema de Informação de Agravos de Notificação (SINAN) e do Sistema Nacional de Notificação de Malária (SIVEP-Malária) foram utilizados para a construção de séries históricas de casos das doenças no período de estudo (Conselho Nacional de Saúde - CONEP; Certificado de Apresentação para Apreciação Ética - CAAE: 20188213.9.0000.5091). O SIVEP-Malária foi também utilizado para a construção de uma série histórica referente ao número de garimpos registrados. Assim, casos de malária foram analisados segundo grupos especiais: área indígena, assentamentos e garimpos.

Considerando-se a dificuldade para registro sistemático e homogêneo dos dados populacionais, optouse aqui pelo uso do número de casos totais, ao invés de taxas de incidência.

\section{ANÁLISE DE VARIAÇÃO CLIMÁTICA}

É amplamente conhecida a correlação direta entre proliferação de insetos vetores e os índices pluviométricos, de temperatura e de umidade, especialmente em casos de doenças como malária e leishmanioses (Chaves; Pascual, 2006; Olson, 2009). Mudanças no microclima regional podem ser desencadeadas tanto por impactos restritos quanto por uma conexão em rede com o clima do planeta, em que pautas como o aquecimento global e eventos sazonais como El Niño e La Ninã afetam a incidência de doenças (Hunter, 2003). No intuito de compreender os efeitos da variação climática e de entender se a ocorrência de eventos climáticos abruptos ou intensos pode explicar o aumento repentino de doenças na região, foram construídas curvas históricas de precipitação total, temperatura máxima média e umidade relativa do ar, referente aos anos de 2003 a 2015. Para tal análise, foram utilizados dados mensais disponíveis na internet do Instituto Nacional de Meteorologia (INMET). Uma curva mediana foi construída para cada variável, sendo vista como referência, de forma que foram considerados atípicos anos que apresentaram valores superiores ou inferiores ao desvio padrão da mediana.

\section{ANÁLISE ESPACIAL}

Realizou-se uma análise histórica de taxas de desmatamento na área de estudo por meio de técnicas de sensoriamento remoto. Foram utilizados vetores referentes às áreas 
desmatadas no Amapá, áreas de conservação e assentamentos, fornecidos formalmente pela Secretaria de Estado do Meio Ambiente do Amapá (SEMA-AP), produzidos a partir de imagens dos satélites LANDSAT 5, referentes aos anos de 2002, 2004, 2007, 2009, e do sistema RAPID-EYE para o intervalo de 2012 a 2015. Coordenadas geográficas referentes à localização de lugares de interesse do estudo foram coletadas em atividades de campo, executadas entre 2012 e 2016. O software Quantum GIS 2.8.2 foi utilizado para cálculo das áreas desmatadas, das distâncias e para o georreferenciamento de dados das localizações de empreendimentos.

\section{RESULTADOS E DISCUSSÃO}

\section{MARCOS TEMPORAIS}

\section{Mineração}

A análise encontrou dezenas de reportagens que relatam, em sua grande maioria, ações públicas contra improbidades das sucessivas empresas que se instalaram na região. Os estudos de Monteiro (2005), Gonçalves (2009), Silva, A. (2014), Vilhena (2014) e Juarez (2015) trazem boas descrições do cenário de mineração no Amapá, com foco sobre a região e o período de estudo.

A mineração de manganês, estabelecida desde a década de 1950 no município de Serra do Navio pela empresa britânica Indústria e Comércio de Minérios S.A. (ICOMI), representa historicamente o processo de desenvolvimento econômico e de infraestrutura no Amapá. Com a paralisação da operação da mina de manganês no ano de 1997, quebrou-se uma lógica inercial de cinco décadas de operação na região. Desde então, a expansão da mineração se deu em direção ao município vizinho de Pedra Branca do Amapari. Atualmente, nove empresas realizam atividade de mineração industrial, sendo seis em Pedra Branca do Amapari e três em Serra do Navio.
Em Pedra Branca do Amapari, as principais explorações são de ouro e de ferro (Gonçalves, 2009). $\bigcirc$ projeto Amapari foi o pioneiro neste município em relação à mineração de ouro, no princípio dos anos 1990, através da empresa Anglo Gold. Em 2003, esta foi adquirida pela EBX Gold, do grupo EBX, que controla também a MMX Amapá Mineração Ltda., dona dos diretos de exploração de ferro na área da Mineração Pedra Branca do Amapari (MPBA). Como marco de impacto importante, destaca-se a realização de uma Ação Civil Pública (ACP) ${ }^{5}$, pelo Ministério Público Federal (MPF), em outubro de 2006, na qual a MMX é acusada de ter construído sua usina em Pedra Branca do Amapari sem aprovação do EIA e sem quaisquer consultas prévias às comunidades residentes na região. Segundo Juarez (2015, p. 84):

\section{[...] a empresa MPBA buscava uma espécie de trocas de favores, satisfazendo necessidade da comunidade que não tinham relação com sua finalidade local. [...] $\bigcirc$ que a empresa esperaria na devolução dessas doações representa a motivação e a identidade com a finalidade do projeto de mineração. A vantagem de ser 'próximo' da comunidade é que a empresa passaria a gozar de relação de cumplicidade quando precisasse de um aval moral da comunidade.}

Entre 2005 e 2007, surgiram dois projetos voltados à exploração mineral nos municípios em questão. O primeiro, da empresa MPBA, de extração de ouro a céu aberto. A empresa produziu entre 2005 e 2009 cerca de nove toneladas de ouro (Oliveira, M.; Mathis, 2017). Em 2010, passou para o controle da australiana Beadell Resources, que ampliou as estruturas de instalação e retomou a produção, em 2013, tornando-se uma das maiores empresas de exploração de ouro em território brasileiro. A mina Tucano, localizada a menos de $50 \mathrm{~km}$ do limite sul da TIW, abrange uma área aproximada de 2,5 mil km². Segundo dados do site da empresa (Beadell, 2017), em 2015 ela movimentou 156 mil toneladas de minério na mina de Tucano.

\footnotetext{
A ACP está em trâmite na $2^{\text {a } V a r a ~ F e d e r a l ~ d e ~ M a c a p a ́, ~ A m a p a ́ . ~}$
}

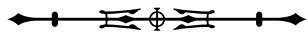


Dados de Juarez (2015) apontam que o número de empregos vinculados à mineração no município de Pedra Branca do Amapari cresceu 266\% entre 2010 e 2014.

Em 2016, a Beadell foi multada pelo Instituto de Meio Ambiente e Ordenação Territorial do Amapá (IMAP) em dois milhões de reais, por descumprir treze condicionantes das licenças, e mais cinco milhões de reais, por contaminação do solo. Após alguns meses, a empresa anunciou ter encontrado mais uma área com ouro de alto teor na mina Tucano. De acordo com reportagem publicada no portal do G1,

Segundo a Beadell, a mina com ouro de alto valor foi constatada em pesquisas feitas em 25 furos de sondagens em uma área com profundidade de 100 metros, com espessuras médias de 20 metros no setor norte da Tucano [...] a menos de dois quilômetros da cava principal da mina a céu aberto (Santiago, 2016, não paginado).

Segundo Gonçalves (2009, p. 75):

$[\ldots]$ tanto o ouro $[\ldots]$ quanto o ferro $[. .$.$] são lavrados$ por métodos tradicionais a céu aberto (superficial), o mesmo acontecendo com a atividade informal, a garimpagem. [...] nas atividades a céu aberto, tem-se um maior aproveitamento da substância mineral, porém é neste tipo de lavra que acontecem os maiores riscos de impactos ambientais, produzindo maior quantidade de estéril, poeira em suspensão, vibrações e riscos de poluição das águas.

Em relação à produção de minério de ferro na região de Pedra Branca do Amapari, ressalta-se a atuação, a partir de 2007, da MMX Amapá Mineração Ltda. Com o ambicioso Projeto Ferro MMX Amapá, a empresa previa a produção de 6,5 milhões de toneladas de minério por ano, com uma vida útil de 20 anos (Minério..., 2006). O projeto foi interrompido com a venda para o grupo Anglo American (Oliveira, M., 2010). A nova empresa, Anglo Ferrous Amapá, atingiu a produção máxima (6,5 Mton) em 2012 (Oliveira, M.; Mathis, 2017).

No início de 2013, a mineradora do Grupo Zamin adquiriu o controle do empreendimento, que atuava de forma limitada desde 2007. Esse movimento impulsionou a migração populacional no município de Pedra Branca do Amapari, que, segundo dados do Instituto Brasileiro de Geografia e Estatística (IBGE), cresceu mais de 400\% entre os anos de 1996 e 2014 (Juarez, 2015).

Em 2014, o Ministério Público do Estado do Amapá (MP-AP), por meio das promotorias dos municípios de Serra do Navio e de Pedra Branca do Amapari, instalaram a Ação Cautelar n. 400/2014 contra a empresa Zamin, exploradora do minério de ferro, sob acusações de sonegação fiscal e de corrupção dos trâmites de indenização e de compensações por danos ambientais. Ao final desse ano, a Zamin interrompeu suas atividades por dificuldades logísticas e incapacidade de estocar o minério (Cavalcanti, 2017).

\section{Usinas hidrelétricas}

A partir da segunda metade da década de 1990, com a retomada do crescimento econômico brasileiro e o consequente consumo de energia, o governo propôs a construção de novas hidrelétricas na Amazônia e a (re) potencialização de usinas antigas - como é o caso da Usina Hidrelétrica de Coaracy Nunes (UHCN), único empreendimento do Amapá até então. Pretendeu, ainda, interligar a geração de energia na Amazônia ao sistema nacional e aos sistemas isolados, atendendo, assim, à demanda crescente da indústria (Silva, C. et al., 2016; Pantoja et al., 2012). No bojo dessas propostas, delineouse o projeto de implantação das hidrelétricas Ferreira Gomes e Cachoeira Caldeirão, como parte do segundo Programa de Aceleração do Crescimento (PAC-2).

A UHE Ferreira Gomes foi leiloada em 2010. Estudos como o de Cunha et al. (2013, p. 67), realizando uma simulação anterior ao início da construção da usina, indicaram os seguintes impactos possíveis: "[...] provável alteração significativa, tanto das características geométricas do canal natural quanto do comportamento hidrodinâmico dos campos de dispersão de agentes passivos na água". Apontaram, ainda, que o período "[...] hidrológico sazonal 
menos chuvoso seria o mais crítico no controle das vazões de montante, principalmente em função da operação simultânea da UHCN" (Cunha et al., 2013, p. 67), também localizada no rio Araguari, a cerca de $15 \mathrm{~km}$ de Ferreira Gomes e em exercício há 40 anos.

Em junho de 2011, a Secretaria Estadual do Meio Ambiente (SEMA-AP) concedeu a licença de instalação da UHE Ferreira Gomes, e a implantação do canteiro de obras teve início em novembro do mesmo ano. Ainda em 2011, a Associação Comercial de Ferreira Gomes protocolou, no MPF, uma denúncia contra a empresa Ferreira Gomes Energia. A empresa estaria descumprindo algumas cláusulas condicionantes para validação da licença prévia de instalação, especialmente as de compensação social e econômica, estando em desacordo com o que fora estabelecido pela SEMA-AP à época da emissão do documento, em 2010 (Silva, C. et al., 2016).

Em março de 2012, as obras da Usina Hidrelétrica Ferreira Gomes entraram em nova etapa. Com o encerramento da escavação no leito do rio Araguari, iniciou-se a concretagem da área de montagem, espaço no qual foram colocadas as turbinas antes de sua instalação na casa de força.

Em agosto de 2012 e novembro de 2013, a Secretaria de Vigilância em Saúde do Amapá (SVS-AP) emitiu atestados de condição sanitária (ATCS, 2012, 2013) ao empreendimento, alegando

[...] aptidão para continuidade do processo de licenciamento junto aos órgãos estaduais e afins, por estar cumprindo os requisitos necessários à prevenção e ao controle da malária e de seus vetores, conforme determina a Resolução CONAMA 286/2001.

Entre os anos de 2010 e 2013, foram emitidas, pelos órgãos competentes, autorizações para a supressão vegetal (desmatamento) e queima de uma área que totaliza 1.063 hectares de floresta ${ }^{6}$. Ao final de 2014, a UHE Ferreira Gomes entrou em funcionamento a cerca de $20 \mathrm{~km}$ da UHE Cachoeira Caldeirão, cujas obras foram iniciadas em agosto de 2013.

Entre abril e novembro de 2014 sucederam-se quatro eventos de alta mortandade de peixes às margens do rio Araguari, gerando grande mobilização da população de Ferreira Gomes. O laudo emitido pelo Instituto do Meio Ambiente e Ordenação Territorial do Amapá (IMAP) "[...] descartou a hipótese de poluição do rio, [...] o laudo relata que os peixes apresentavam [...] indícios de embolia gasosa provocada pela supersaturação da água liberada pelo vertedouro da usina de Cachoeira Caldeirão" (GEA, 2016 apud Silva, C. et al., 2016, p. 136).

Em janeiro de 2015,

[...] a abertura das comportas da UHE Cachoeira Caldeirão impactaram diretamente na elevação do rio Araguari, [...] onde a cheia atingiu 5,5 metros. Isto corresponde a 2,3 metros acima do considerado normal para a região [...] (Silva, C. et al., 2016, p.135).

A cheia do rio atingiu cerca de 1,4 mil pessoas e ocorreu após abertura das comportas. Durante esse evento, duas pessoas morreram, ruas foram alagadas e muitas famílias perderam casas e bens. Um laudo de engenharia legal revelou que "[...] não há Plano de Ação Emergencial (PAE) conjunto [...] entre as barragens em operação UHE de Coaracy Nunes e UHE Ferreira Gomes, em construção, UHE - Cachoeira Caldeirão" (GEA, 2015 apud Silva, C. et al., 2016, p. 136). Todavia, Silva, C. et al. (2016, p. 136) destacam que "[...] há de se compartilhar a responsabilidade de dano ambiental, trata-se de um processo em cadeia, pois existe um conjunto de usinas operando no rio".

Em junho de 2015, manchetes anunciaram o fim da pororoca na foz do rio Araguari, a qual corresponde a um fenômeno natural decorrente do encontro das águas oceânicas, em nível mais elevado, com as correntes fluviais

\footnotetext{
6 Série de quatro documentos emitidos pelo IBAMA e pelo IMAP entre 2010 e 2013 (Ferreira Gomes Geração de Energia, [2018]).
}

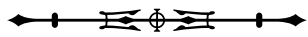


em menor nível de alguns rios que desembocam no mar. Segundo Alves, R. (2015):

\begin{abstract}
O desmatamento para formação espontânea de pastagens, a abertura de canais nas margens do rio pela intensa atividade de bubalinos e a redução da vazão do rio, provocada pelo represamento das hidroelétricas, inegavelmente se somam para o assoreamento da foz do rio Araguari [e o fim do fenômeno hídrico da pororoca].
\end{abstract}

Em uma longa sessão de justificativas, "[...] nenhuma das empresas assume a sua parcela de responsabilidade nos sucessivos [...] acontecimentos no rio Araguari [...]" (Silva, C. et al., 2016, p. 137). Essas ocorrências tornaram-se objeto da Ação Civil Pública n. 01627-41.2015, impetrada pelo Ministério Público em desfavor da Ferreira Gomes Energia S/A, pelo motivo de dano ao meio ambiente, a qual ainda está em andamento.

Além disso, por descumprimento de licenças ambientais e visando reparação de danos morais coletivos causados às comunidades de Porto Grande e de Ferreira Gomes, o MPF-AP ingressou com uma ação civil pública (ACP) contra as empresas Energias do Brasil S/A (EDP) e Empresa de Energia Cachoeira Caldeirão (EECC), em razão do não cumprimento do Convênio n. 002/2014, que trata da adoção de medidas para a melhoria na infraestrutura de saúde e no monitoramento e controle de malária, estabelecidas nas condicionantes para o licenciamento ambiental.

\section{Marcos temporais na Terra \\ Indígena Wajãpi}

Em 2012, indicativos de desequilíbrios ambientais de grande escala foram reportados por muitos Wajãpi: um considerável aumento do número de animais de caça foi identificado na porção sul da estrada, algo que não se via há tempos; a presença incomum de onças adentrando simultaneamente algumas aldeias Wajãpi em dezembro de 2012; uma onda de ataques causados por morcegos hematófagos a crianças Wajãpi, no segundo semestre de 2013; uma sensível alteração no fluxo de alguns rios que permeiam a TIW foi observada, com aumento no volume e na velocidade das águas, que resultaram em acidentes com pequenas embarcações.

Tais acontecimentos trouxeram à tona a hipótese de que esses fatores também poderiam estar relacionados aos desequilíbrios e aos efeitos em cascata provocados pelos empreendimentos ora relatados.

\section{ANÁLISE CLIMÁTICA}

A Figura 1 apresenta as curvas climáticas e as curvas de casos de malária e de LTA na região de estudo. Não houve correlação estatisticamente significativa entre nenhuma das variáveis climáticas e casos de LTA ou de malária. No entanto, a análise descritiva permite observar que, em 2014 e 2015, período em que os casos das duas doenças aumentaram significativamente, houve grande variação da umidade relativa do ar, marcada pela redução abrupta e significativa em relação à média esperada para a região. Tal variação mostra-se semelhante à observada por Mourão (2013), que notou picos de malária nos períodos com menor umidade média anual em alguns municípios do estado do Amapá. Porém, este aspecto não pode ser considerado isoladamente.

No caso do vetor da malária, a redução do número de criadouros (Consoli; Oliveira, R., 1998) depende de uma combinação dos três fatores aqui analisados (Gosoniu et al., 2009). O Anopheles deposita seus ovos em forma de 'jangada' e necessita de águas calmas (Consoli; Oliveira, R., 1998); o excesso ou a escassez de chuvas podem ocasionar a secagem ou o transbordamento de criadouros, dificultando o aumento da densidade populacional do vetor. Assim, sob pluviosidade constante, variações de umidade e de temperatura podem ser determinantes para a dinâmica dos criadouros. No caso de flebotomíneos, vetores da Leishmania, a formação de criadouros se dá em ambientes terrestres ricos em matéria orgânica, e a sua densidade é também frequentemente correlacionada a variações da umidade relativa do ar (URM) (Brazil, R.; Brazil, B., 2003).

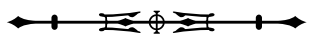




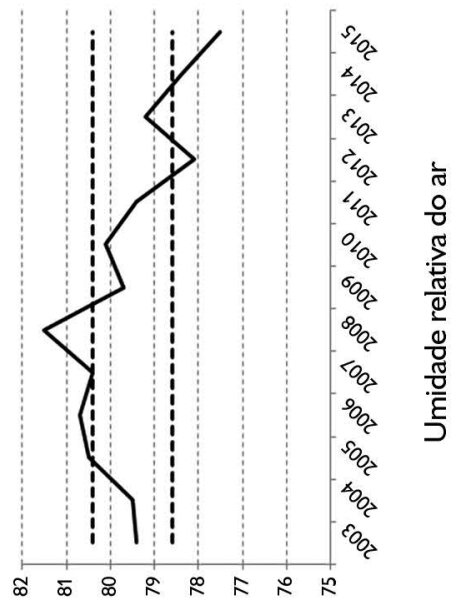

1

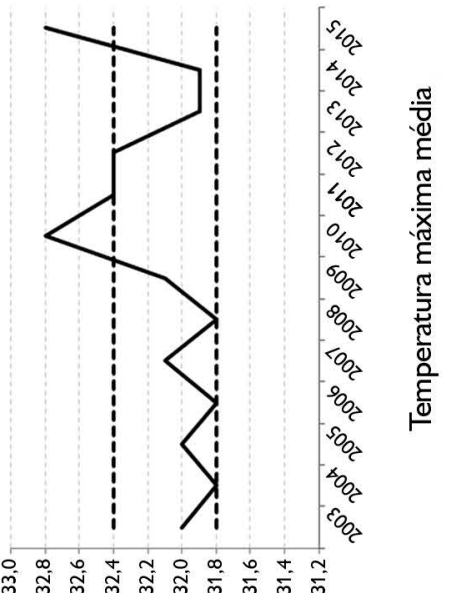

U

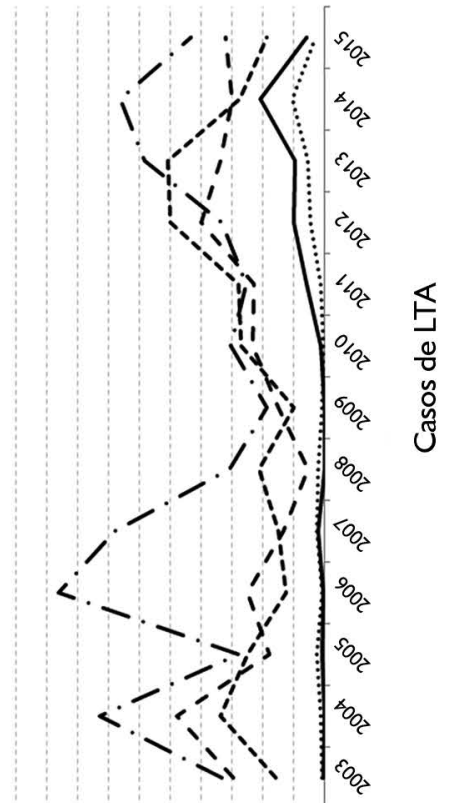

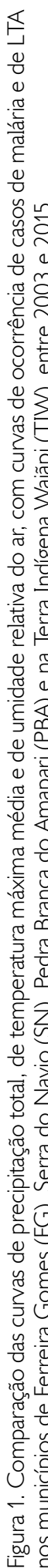

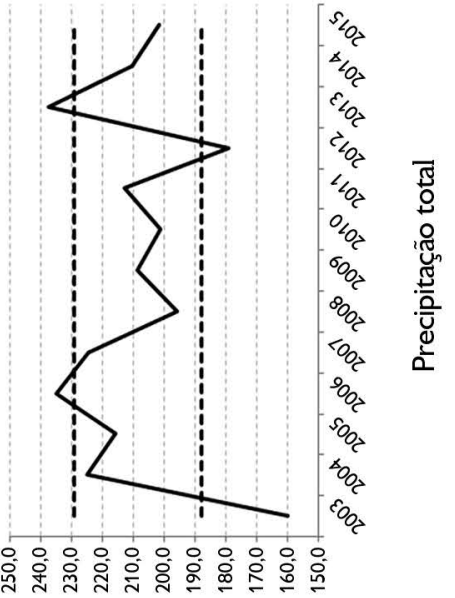

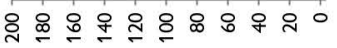

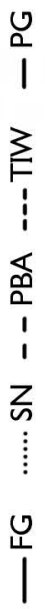
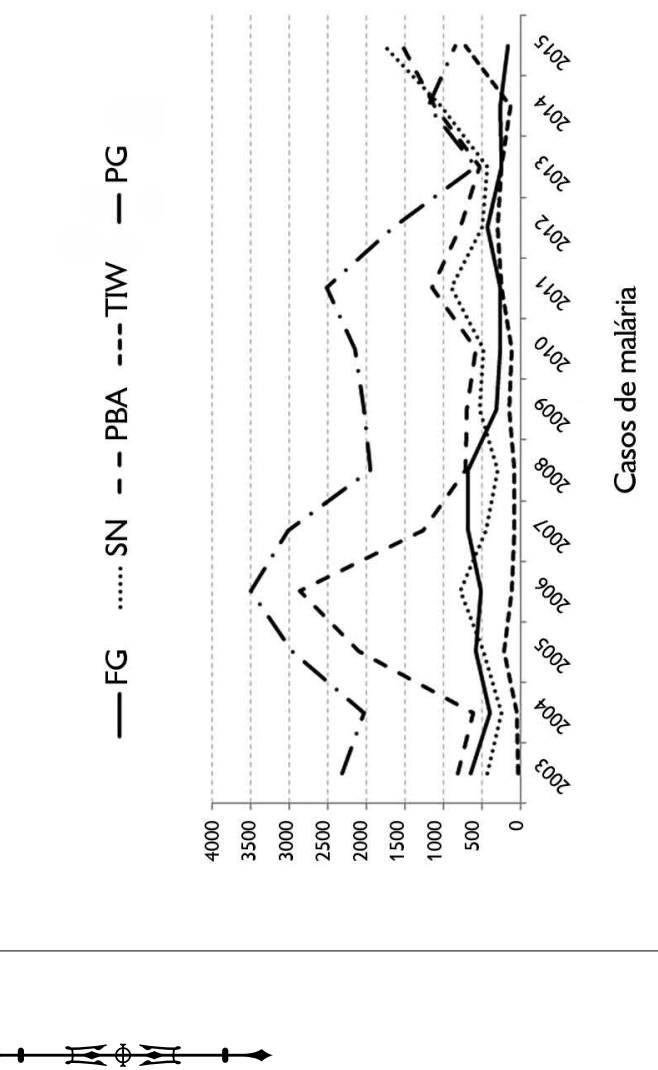
Na Figura 1, é possível constatar constância de pluviosidade, queda significativa da umidade relativa do ar e variação abrupta da temperatura. Observa-se também queda da pluviosidade a partir de 2012-2013 e aumento abrupto deste fator entre 2014-2015. Nesta ondulação, ocorre na TIW recorde de casos de LTA em 2014, seguido de recorde de casos de malária em 2015. Em relação à malária, o número de casos na TIW aumentou de 138, em 2014, para 715, em 2015.

Apesar da identificação da correlação entre variações climáticas abruptas e aumento da incidência de malária e de LTA, essas variações não são suficientes para explicar o fenômeno, nem como suas especificidades regionais se apresentam de fato, principalmente porque, provavelmente, alguns fatores socioambientais de cada região contribuem de modo distinto no processo, e não podem ser generalizados nas análises dos modelos climáticos. Nesse sentido, tais fatores seriam predisponentes, mas não determinantes quando isolados desses surtos.

Mourão (2013) sugere que variações climáticas e aumento de casos de malária no município de Pedra
Branca do Amapari teriam forte correlação com a extração de minérios na região, em que a formação de cavas e de depositórios de rejeitos, entre outros aspectos, favoreceria a constituição de criadouros.

\section{ANÁLISE ESPACIAL}

A Figura 2 demonstra que os casos de malária estiveram correlacionados ao número de garimpos registrados nos municípios em foco no estudo. Picos de casos de malária coincidem com o aumento do número de garimpos e de assentamentos registrados no SIVEP-Malária.

Diferentemente das grandes minerações, garimpos pequenos são móveis e dinâmicos, sendo uma tarefa difícil a sua demonstração através de imagens de satélite, uma vez que não é necessário o desmatamento de grandes áreas para sua realização. Garimpos são conhecidos como importantes fontes de manutenção da malária, pelas péssimas condições sanitárias, grande densidade de pessoas e a já comprovada presença de indivíduos com infecção assintomática pelo plasmódio (Andrade et al., 1995; Barbieri; Sawyer, 2007).

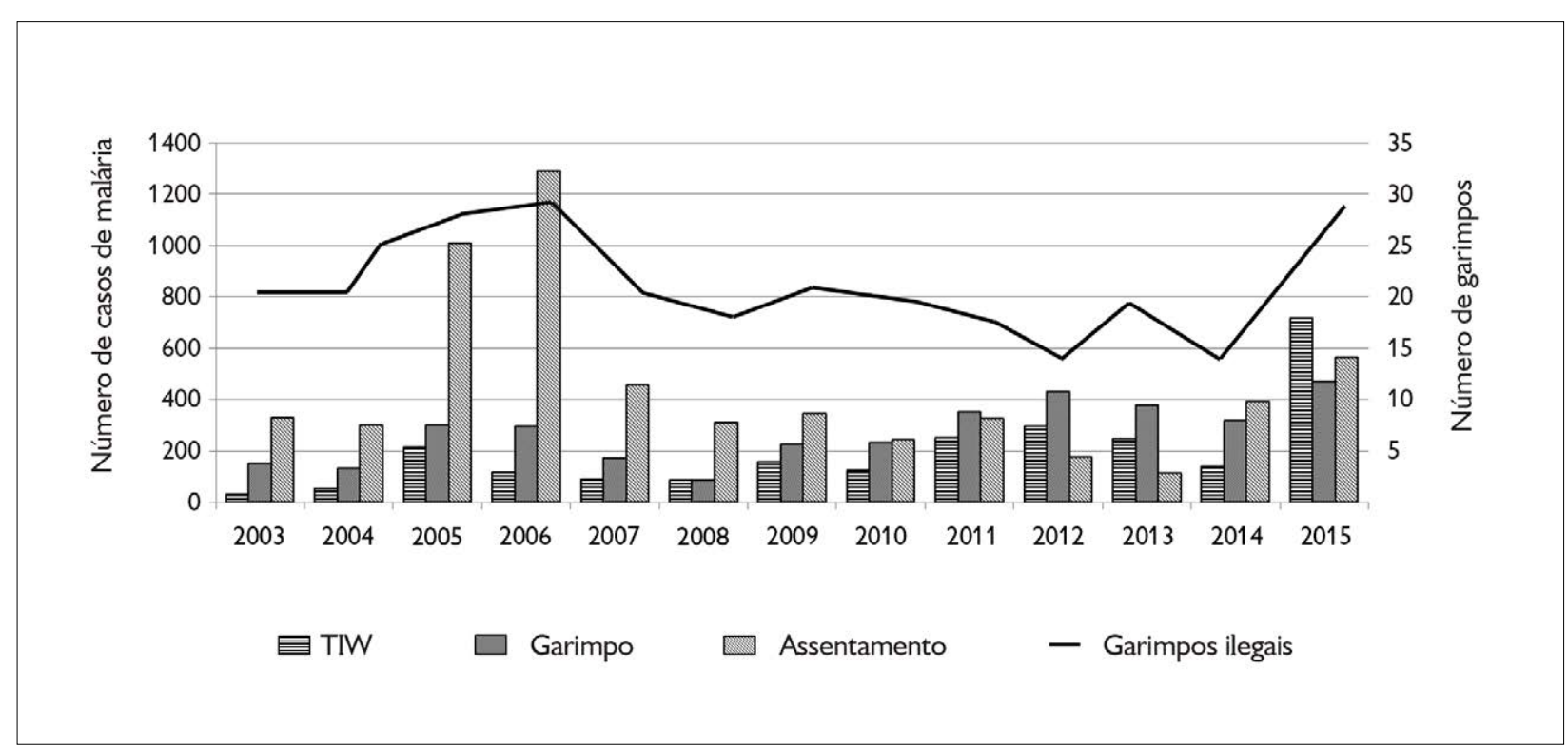

Figura 2. Comparação das curvas de casos de malária na Terra Indígena Wajãpi (TIW), em garimpos e em assentamentos nos municípios de Ferreira Gomes, Porto Grande, Pedra Branca do Amapari e Serra do Navio, e o número de garimpos ilegais registrados na região, entre 2003 e 2015.

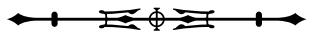


Contrapondo uma das justificativas para a extinção da RENCA em agosto de 2017 - de que pequenos garimpos ilegais tendem a diminuir no contexto de implantação de mineração industrial regulamentada -, observou-se, neste estudo, que foi maior o número de garimpos registrados no SIVEP-Malária na região justamente nos momentos de intensificação das atividades legais de mineração (2005 e 2006), ocorrendo novamente a partir de 2010. Esses eventos estiveram, por sua vez, relacionados a recordes do número de casos de malária e de LTA na região nos mesmos períodos.

A Figura 3 apresenta os dados de desmatamento na área de estudo.

A análise permite-nos observar que, entre os anos de 2003 e 2004, houve a maior taxa de desmatamento no período de estudo, sendo que áreas de mineração próximas aos municípios de Pedra Branca do Amapari e de Serra do Navio se destacam, assim como aquelas localizadas no município de Porto Grande. Nestes anos, assentamentos demonstraram grande taxa de desmatamento em comparação a outros tipos de uso da terra. $O$ assentamento com maior taxa de desmatamento foi o Perimetral Norte, próximo a TIW. Esse período é também marcado por grandes surtos de malária e de LTA em toda área de estudo, principalmente nos municípios de Pedra Branca do Amapari, Serra do Navio e Porto Grande (Figura 1). Na Figura 2, enfatiza-se como, entre 2005 e 2006 - período subsequente à grande onda de desmatamento ocorrida em 2003 e 2004 -, houve um surto recorde de malária, principalmente atrelado aos assentamentos e à variação do número de garimpos. A análise mostra, ainda, que o desmatamento e os casos de malária em assentamentos, garimpos e na TIW estão relacionados com variações proporcionais.

Porém, apesar de o desmatamento ser um conhecido fator para desencadeamento de surtos de malária e de leishmanioses (Araújo-Filho, 1981), observa-se que, isoladamente, não é capaz de explicar a ocorrência

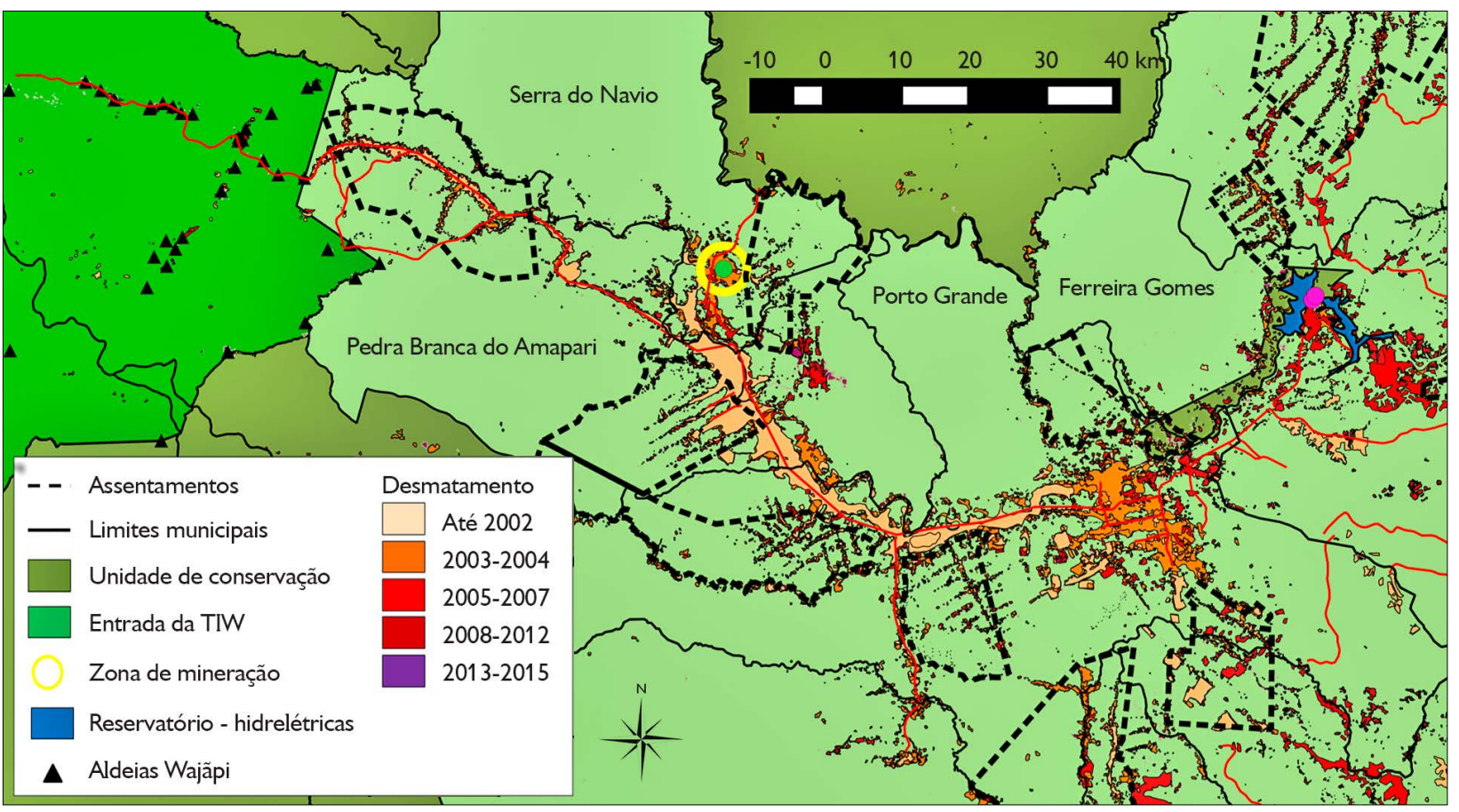

Figura 3. Área de estudo e localização dos impactos ambientais identificados: mineração, usinas hidrelétricas e desmatamento entre os anos de 2002 e 2015. Mapa: Eduardo S. Moreno (2018).

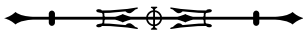


de tais surtos. Apesar de ter sido observada uma menor taxa de desmatamento entre o período de 2012 e 2015, comparado a períodos anteriores, um novo pico destas doenças volta a acontecer nos municípios em foco e na TIW (Figura 1). Porém, tal aumento de casos de malária não é observado em Ferreira Gomes e Porto Grande, municípios mais próximos às usinas hidrelétricas. Isso pode ser explicado pelo fato de esses últimos terem recebido atenção do plano de controle de malária, previsto na mitigação de impactos, no contexto da construção e da instalação das usinas hidrelétricas. A Figura 4 apresenta o número de exames de malária realizados através de busca ativa na área de estudo, entre os anos de 2010 e 2015, e evidencia a desproporcional superioridade da vigilância da malária empregada em Ferreira Gomes e Porto Grande, em comparação com os demais municípios, quando da implantação das UHE.

A Figura 4 demonstra como o número de exames realizados por busca ativa de casos variou em mais de 1.000\% em um período de cinco anos em Ferreira Gomes e em Porto Grande, com incremento abrupto em 2010 e pico em 2013, além de queda também repentina em 2015. Esta variação não foi demonstrada nos demais municípios e na TIW. Tal achado é semelhante ao padrão observado na usina de Belo Monte, no Pará, em que as ações de controle implementadas pela empresa, com apoio do Ministério da Saúde, foram capazes de reduzir a incidência de malária na área de influência direta da usina (CTMC, [2014-2015]).

Além disso, como apresentado na Figura 1, um grande surto de LTA ocorreu no mesmo período, com pico em 2014, simultaneamente em toda a área de estudo. Enquanto a malária é sabidamente passível de controle - pela quebra de sua cadeia de transmissão a partir da identificação de casos e de tratamento oportuno, uma vez que o homem é um importante hospedeiro para infecção de mosquitos vetores -, na LTA, o homem é um hospedeiro final e pouco contribui para a transmissão direta do parasito a flebotomíneos, dependendo muito

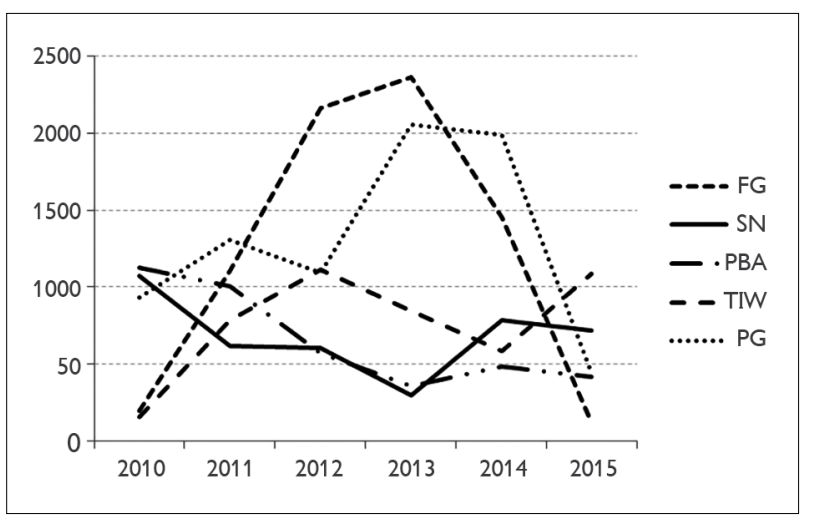

Figura 4. Número de exames para diagnóstico de malária realizados por busca ativa nos municípios de Ferreira Gomes (FG), Porto Grande (PG), Serra do Navio (SN), Pedra Branca do Amapari (PBA) e na Terra Indígena Wajãpi (TIM), entre os anos de 2010 e 2015.

mais da alteração da comunidade de fauna de hospedeiros silvestres. Nesse sentido, identificação e tratamento de casos não repercutem em interrupção da cadeia de transmissão da LTA, como demonstrado na Figura 2, em que todos os municípios evidenciaram aumento no número de casos.

Assim, a mobilidade e a migração populacional são mais importantes para a ecologia da malária do que da LTA, que depende mais da modificação ambiental, causada por impactos antropogênicos. A TIW possui uma vulnerabilidade diferenciada dos municípios estudados, uma vez que há um descompasso entre o modo de vida Wajãpi e as ações de saúde pública. As aldeias Wajãpi são bastante dispersas pelo território, algumas delas com distâncias percorridas a pé por até dez dias de caminhada. Elas não estão cobertas pela forma como o Estado planeja e executa os serviços de saúde, que são centralizados em alguns pontos da TIW e dependem tanto de infraestrutura como de profissionais não indígenas, de modo que pequenos surtos em aldeias afastadas geram riscos mais significativos de morbidade/óbito. De 2012 até 2015, apenas um agente de endemias era responsável por uma área de 600 mil hectares e 80 aldeias de acesso variável. Em 2013, dois óbitos por malária ocorreram na região, devido às dificuldades de deslocamento ao posto de saúde.

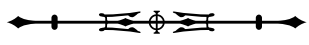


Portanto, evidencia-se que tais surtos de malária e de LTA não podem ser desvinculados espacial e temporalmente dos eventos envolvendo desmatamento, mineração e da implantação de usinas hidrelétricas na região. $\bigcirc$ grande número de impactos ambientais em série evidencia também a ineficiência dos processos de licenciamento ambiental para prever e controlar a repercussão de tais efeitos sobre a saúde das populações, demonstrando que a conectividade ecológica e social projeta tais impactos para uma área muito superior a dos poucos quilômetros considerados como área de influência destes empreendimentos. Assim, a saúde das populações afetadas direta e indiretamente por empreendimentos econômicos não pode ser considerada apenas como uma externalidade pelo empreendedor. A saúde precisa ser avaliada de forma integrada aos fatores sociais e ecológicos, para que seja resguardada ou incrementada a qualidade de vida das populações de uma determinada região (Silveira et al., 2012), se contrapondo ao que o Breilh (2006, p. 26) chama de:

[...] a epidemiologia dos mínimos de sobrevivência (bottom-line epidemiology), instrumento necessário da concepção de estratégia do neoliberalismo. [...] a lógica que substitui as aspirações máximas de saúde integral de um povo pela lógica dos mínimos toleráveis no âmbito da governabilidade - cálculo da redução máxima dos gastos sociais, dentro dos limites permitidos pela governabilidade e pela legitimação do sistema.

\section{CONCLUSÃO}

Éfundamental que avaliações de impacto ecoepidemiológico para definição de áreas de influência de grandes empreendimentos sejam realizadas de forma não limitada ao conceito de distância, mas orientadas por eixos de conexão ecológicos e sociais, que podem variar de poucos a centenas de quilômetros, ou nem mesmo estarem conectados fisicamente.

O caso estudado ilustra, ainda, a necessidade de ampliação do escopo de doenças sob foco em estudos de licenciamento ambiental, que, atualmente, apenas preveem uma investigação de potencial malarígeno e plano de controle para malária. Portanto, recomendase fortemente que sejam regulamentados estudos de potencial e de planos de controle para doenças como as leishmanioses e outras doenças transmitidas por vetores com ciclos ambientais complexos, como as arboviroses. A raiva também mostra-se com importante incremento de risco em áreas amazônicas sob impacto ambiental.

Este trabalho evidencia a grave situação desencadeada pelo desenvolvimento político neoliberal na Amazônia, através de projetos como a extinção da RENCA, e o esforço de determinados setores político-econômicos para a modificação da legislação relacionada ao licenciamento ambiental, por meio da PEC 65/2012. Esperamos ter reforçado a necessidade da inclusão de fatores relacionados à saúde e da normatização de indicadores mais específicos nas avaliações de impacto ambiental, para que tais aspectos venham a compor os subsídios necessários aos processos de tomada de decisão e às políticas públicas, de modo a torná-las mais favoráveis à promoção da qualidade de vida, respeitando os modos de existência de comunidades indígenas.

\section{REFERÊNCIAS}

ALBERT, Bruce. O ouro canibal e a queda do céu: uma crítica xamânica da economia política da natureza (Yanomami). In: ALBERT, Bruce; RAMOS, Alcida Rita (Org.). Pacificando o branco: cosmopologias do contato no norte-amazônico. São Paulo: Unesp, 2002. p. 239-276

ALVES, Raimundo Nonato Brabo. As pororocas do rio Araguari no Amapá foram extintas pela mão do homem. EcoDebate, Rio de Janeiro, 23 jul. 2015. Disponível em: <https://www.ecodebate. com.br/2015/07/23/as-pororocas-do-rio-araguari-no-amapa-foramextintas-pela-mao-do-homem-artigo-de-raimundo-nonato-braboalves/>. Acesso em: 20 jul. 2016

ANDRADE, Ana Lucia S. S. de; MARTELLI, Celina M. T.; OLIVEIRA, Renato M.; ARIAS, Jorge R.; ZICKER, Fabio; PANG, Lorin. High prevalence of asymptomatic malaria in gold mining areas in Brazil. Clinical Infectious Diseases, Oxford, v. 20, n. 2, p. 475, Feb. 1995.

ANTUNES, Paulo de Bessa. Direito ambiental. Rio de Janeiro: Editora Lumen Juris, 2008.

ARAÚJO FILHO, Nelson A. de. Leishmaniose Tegumentar Americana e o desmatamento da Amazônia. Acta Amazonica, Manaus, v. 11, n. 1, p. 187-189, mar. 1981. DOI: http://dx.doi. org/10.1590/1809-43921981111187.

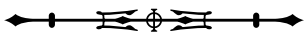


ATESTADO DE CONDIÇÃO SANITÁRIA (ATCS). ATCS n. 001/2013. Processo n. 2013/42025. Macapá: Coordenadoria de Vigilância em Saúde, 2013. Disponível em: <http://ferreiragomesenergia.com.br/wp-content/uploads/ sites/3/2018/04/2013.11.29-Atestado-de-Condi\%C3\%A7\% C3\%A3o-Sanit\%C3\%A1ria-N\%C2\%BA-012013.pdf>. Acesso em: 15 dez. 2017.

ATESTADO DE CONDIÇÃO SANITÁRIA (ATCS). ATCS n. 002/2012. Processo n. 48240/2012. Macapá: Coordenadoria de Vigilância em Saúde, 2012. Disponível em: < http:/fferreiragomesenergia. com.br/wp-content/uploads/sites/3/2018/04/2012.08.10-Atestado-deCondi\%C3\%A7\%C3\%A3o-Sanit\%C3\%A1ria.pdf> . Acesso em: 15 dez. 2017.

BARBIERI, Alisson Flávio; SAWYER, Diana Oya. Heterogeneity of malaria prevalence in alluvial gold mining areas in Northern Mato Grosso State, Brazil. Cadernos de Saúde Pública, Rio de Janeiro, v. 23, n. 12, p. 2878-2886, dez. 2007. DOI: http://dx.doi.org/10.1590/ S0102-311X2007001200009.

BEADELL. Brazilian gold producer with a growing multimillion ounce resource. [Austrália], 2017. Available in: <https:// beadellresources.com.au/about-us/> . Access in: 15 Dec. 2017.

BÉRTOLI, Marta; MOITINHO, Maria da Luz Ribeiro. Malária no estado do Paraná, Brasil. Revista da Sociedade Brasileira de Medicina Tropical, Uberaba, v. 34, n. 1, p. 43-47, jan.-fev. 2001. DOI: http://dx.doi.org/10.1590/\$0037-86822001000100007.

BRANDT, Wilfred; AVELAR, Sérgio. Definições nos processos de licenciamento ambiental e consequências na efetividade de seus resultados. Brandt Meio Ambiente, Minas Gerais, [201-]. Disponível em: <http://brandt.com.br/index.php/publicacoes/detalhes/6>. Acesso em: 15 dez. 2017.

BRASIL. Decreto n. 9.142, de 22 de agosto de 2017. Extingue a Reserva Nacional de Cobre e seus associados, constituída pelo Decreto n. 89.404, de 24 de fevereiro de 1984, localizada nos estados do Pará e do Amapá. Diário Oficial [da] República Federativa do Brasil, Brasília, DF, 23 ago. 2017a. Seção 1, p. 13.

BRASIL. Decreto n. 9.147, de 28 de agosto de 2017. Revoga o Decreto n. 9.142, de 22 de agosto de 2017, que extinguiu a Reserva Nacional do Cobre e seus associados - RENCA e extingue a Reserva Nacional do Cobre e seus associados - RENCA para regulamentar a exploração mineral apenas na área onde não haja sobreposição com unidades de conservação, terras indígenas e faixa de fronteira. Diário Oficial [da] República Federativa do Brasil, Brasília, DF, 28 ago. 2017b. Seção 1, p. 1. Edição Extra.

BRASIL. Decreto n. 9.159, de 25 de setembro de 2017. Revoga o Decreto n. 9.147, de 28 de agosto de 2017, que dispõe sobre a Reserva Nacional de Cobre e seus associados - RENCA, e dá outras providências. Diário Oficial [da] República Federativa do Brasil, Brasília, DF, 26 set. 2017c. Seção 1, p. 1.
BRASIL. Secretaria de Vigilância em Saúde. Dispõe sobre a avaliação do potencial malarígeno e o atestado de condição sanitária para os projetos de assentamento de reforma agrária e para outros empreendimentos, nas regiões endêmicas de malária. Diário Oficial [da] República Federativa do Brasil, Brasília, DF, 4 jan. 2007. Seção 1, p. 66.

BRASIL. Conselho Nacional do Meio Ambiente. Resolução CONAMA n. 286, de 30 de agosto de 2001. Dispõe sobre o licenciamento ambiental de empreendimentos nas regiões endêmicas de malária. Diário Oficial [da] República Federativa do Brasil, Brasília, DF, 17 dez. 2001. Seção 1, p. 223.

BRASIL. Conselho Nacional do Meio Ambiente. Resolução CONAMA n. 009, de 3 de dezembro de 1987. Dispõe sobre a realização de audiências públicas no processo de licenciamento ambiental. Diário Oficial [da] República Federativa do Brasil, Brasília, DF, 5 jul. 1990. Seção 1, p. 12945.

BRASIL. Conselho Nacional do Meio Ambiente. Resolução CONAMA n. 001, de 23 de janeiro de 1986. Dispõe sobre critérios básicos e diretrizes gerais para a avaliação de impacto ambiental. Diário Oficial [da] República Federativa do Brasil, Brasília, DF, 17 fev. 1986. Seção 1, p. 2548-2549.

BRASIL. Decreto n. 92.107, de 10 de dezembro de 1985. Altera o Decreto n. 89.404, de 24 de fevereiro de 1984, que constitui Reserva Nacional de cobre e seus associados a área que menciona, no estado do Pará e no território federal do Amapá. Diário Oficial [da] República Federativa do Brasil, Brasília, DF, 11 dez. 1985. Seção 1, p. 18160.

BRASIL. Decreto n. 89.404, de 24 de fevereiro de 1984. Constitui Reserva Nacional de cobre e seus associados a área que menciona, no estado do Pará e no território federal do Amapá, e dá outras providências. Diário Oficial [da] República Federativa do Brasil, Brasília, DF, 28 fev. 1984. Seção 1, p. 2929.

BRAZIL, Reginaldo Peçanha; BRAZIL, Beatriz Gomes. Biologia de flebotomíneos neotropicais. In: RANGEL, Elizabeth F; LAINSON, Ralph (Org.). Flebotomíneos do Brasil. Rio de Janeiro: Fiocruz, 2003. p. 257-274.

BREILH, Jaime. Epidemiologia crítica: ciência emancipadora e interculturalidade. Rio de Janeiro: Fiocruz, 2006.

BURSZTYN, Maria Augusta; BURSZTYN, Marcel. Fundamentos de política e gestão ambiental: caminhos para a sustentabilidade. Rio de Janeiro: Garamond, 2012.

CÂMARA TÉCNICA DE MONITORAMENTO DAS CONDICIONANTES DA UHE BELO MONTE-(CTMC). Indicadores de Belo Monte - malária. Altamira, [2014-2015]. Disponível em: <www.indicadoresdebelomonte.eco.br>. Acesso em: 12 mar. 2018. 
CAPIBERIBE, Artionka; BONILLA, Oiara. A ocupação do congresso: contra o quê lutam os índios? Estudos Avançados, São Paulo, v. 29, n. 83, p. 293-131, jan.-abr. 2015. DOI: http://dx.doi.org/10.1590/ s0103-40142015000100014.

CAPIBERIBE, Artionka; BONILLA, Oiara. Um gosto amargo de déja $v u$ : desenvolvimento e os índios. Le Monde Diplomatique Brasil, São Paulo, n. 65, dez. 2012. Disponível em: < https://diplomatique. org.br/um-gosto-amargo-de-deja-vu-desenvolvimento-e-osindios/>. Acesso em: 10 abr. 2018.

CARDOSO, Andrey Moreira; HORTA, Bernardo Lessa; COIMBRA JR., Carlos E. A.; FOLLÉR, Maj-Lis; SOUZA, Mirian Carvalho de; SANTOS, Ricardo Ventura. Inquérito nacional de saúde e nutrição dos povos indígenas. Brasília: Fundação Nacional de Saúde, 2009. (Relatório final, n. 7).

CAVALCANTI, Claudia. Plano de recuperação judicial da Zamin pode ser um golpe no AP. Jornal A Gazeta, Macapá, 2 abr. 2017. Disponível em: <http://www.jornalagazeta-ap.com.br/info/ noticia/13756/plano_de_recuperacao_judicial_da_zamin_pode ser_um_golpe_no_apphp $>$. Acesso em: 3 abr. 2017.

CHAGAS, Andrezza Campos; PESSOA, Felipe Arley Costa; MEDEIROS, Jansen Fernandes de; PY-DANIEL, Victor; MESQUITA, Éder C.; BALESTRASSI, Dultevir Antônio. Leishmaniose Tegumentar Americana (LTA) em uma vila de exploração de minérios-Pitinga, município de Presidente Figueiredo, Amazonas, Brasil. Revista Brasileira de Epidemiologia, São Paulo, v. 9, n. 2, p. 186-192, quad. 2006. DOI: http://dx.doi.org/10.1590/S1415-790X2006000200005.

CHAVES, Luis Fernando; PASCUAL, Mercedes. Climate cycles and forecasts of cutaneous leishmaniasis, a nonstationary vector-borne disease. PLoS Medicine, San Francisco, v. 3, n. 8, p. e295, Aug. 2006. DOI: https://doi.org/10.1371/journal.pmed.0030295.

CONCEIÇÃO-SILVA, Fátima; ALVES, Carlos Roberto (Org.) Leishmanioses do continente americano. Rio de Janeiro: Editora Fiocruz, 2014.

CONFERÊNCIA NACIONAL DE MEIO AMBIENTE, 1., 2003, Brasília. Documentos... Brasília: MMA, 2003.

CONSOLI, Rotraut A. G. B.; OLIVEIRA, Ricardo Lourenço de. Principais mosquitos de importância sanitária no Brasil. Rio de Janeiro: Fiocruz, 1998

CONVENÇÃO n. 169 sobre povos indígenas e tribais e Resolução referente à ação da OIT. Brasília: OIT, 2011. 1 v.

COUTO, Álvaro Augusto; CALVOSA, Vanja Suely; LACERDA, Raimundo; CASTRO, Francisco; SANTA ROSA, Edivaldo; NASCIMENTO, José Maria. Controle da transmissão da malária em área de garimpo no estado do Amapá com participação da iniciativa privada. Cadernos de Saúde Pública, Rio de Janeiro, v. 17, n. 4 p. 897-907, jul.-ago. 2001. DOI: http://dx.doi.org/10.1590/S0102$311 \times 2001000400023$
CUNHA, Alan Cavalcanti; CUNHA, Helenilza Ferreira Albuquerque; PINHEIRO, Luis Aramis dos Reis. Modelagem e simulação do escoamento e dispersão sazonais de agentes passivos no rio Araguari AP: cenários para o AHE Ferreira Gomes-I-Amapál Brasil. Revista Brasileira de Recursos Hídricos, Porto Alegre, v. 18, n. 1, p. 67-85, jan.-mar. 2013. DOI: http://dx.doi.org/10.21168/ rbrh.v18n1.p67-85

DUARTE, Elisabeth Carmen; FONTES, Cor Jesus Fernandes. Associação entre a produção anual de ouro em garimpos e incidência de malária em Mato Grosso-Brasil, 1985-1996. Revista da Sociedade Brasileira de Medicina Tropical, Uberaba, v. 35, n. 6, p. 665-668, nov.-dez. 2002. DOI: http://dx.doi.org/10.1590/ S0037-86822002000600020

FEARNSIDE, Philip Martin; LAURANCE, William Frederick. Infraestrutura na Amazônia: as lições dos planos plurianuais. Caderno CRH, Salvador, v. 25, n. 64, p. 87-98, jan.-abr. 2012. DOI: http:// dx.doi.org/10.1590/S0103-49792012000100007.

FEARNSIDE, Philip Martin. Soybean cultivation as a threat to the environment in Brazil. Environmental Conservation, Cambridge, v. 28, n. 1, p. 23-38, Mar. 2001. DOI: https://doi.org/10.1017/ S0376892901000030.

FERREIRA GOMES GERAÇÃO DE ENERGIA. Relatórios. São Paulo, [2018]. Disponível em: <http://ferreiragomesenergia.com. br/relatorios/>. Acesso em: 15 dez. 2017.

FREITAS, Juarez. Sustentabilidade: direito ao futuro. Belo Horizonte: Fórum, 2011

GALLOIS, Dominique Tilkin. Terra Indígena Wajãpi: da demarcação às experiências de gestão territorial. São Paulo: Iepé, 2011. (Coleção Ensaios, 1).

GENEROSO, Francisco Chaves. As condicionantes no licenciamento ambiental de empreendimentos minerários. MPMG Jurídico, Belo Horizonte, p. 17-20, 2012. Edição especial.

GONÇALVES, Paulo Cesar da Silva. Diagnóstico geoambiental do município de Pedra Branca do Amapari, Amapá. 2009. 98 f. Dissertação (Mestrado em Biodiversidade Tropical) - Universidade Federal do Amapá, Macapá, 2009.

GOSONIU, Laura; VOUNATSOU, Penelope; SOGOBA, Nafomon; MAIRE, Nicolas; SMITH, Thomas A. Mapping malaria risk in West Africa using a Bayesian nonparametric non-stationary model. Computational Statistics \& Data Analysis, Amsterdam, v. 53, n. 9, p. 3358-3371, July 2009. DOI: https://doi.org/10.1016/j. csda.2009.02.022.

GOVERNO DO ESTADO DO AMAPÁ (GEA). IMAP e SEMA investigam causas de morte de peixes no Rio Araguari. Macapá: IMAP, 2016. Disponível em: <https://www.portal.ap.gov.br/ noticia/3005/imap-e-sema-investigam-causas-de-morte-de-peixesno-rio-araguari>. Acesso em: 13 mar. 2016.

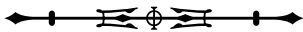


GOVERNO DO ESTADO DO AMAPÁ (GEA). Laudo $\mathbf{n}$. 49.945/2015-DC/Politec - Laudo de exame de corpo de delito de engenharia legal. Macapá: POLITEC, 2015.

HEURICH, Guilherme Orlandini. Impactos imediatos e futuros: os Araweté e os executores do Plano Emergencial de Belo Monte. In: INSTITUTOSOCIOAMBIENTAL (ISA). Vozes do Xingu: coletânea de artigos para o Dossiê Belo Monte. São Paulo: Instituto Socioambiental, 2015. p. 76-78.

HUNTER, Paul R. Climate change and waterborne and vectorborne disease. Journal of Applied Microbiology, Bethesda, v. 94, p. 37-46, Apr. 2003. Supplement. DOI: https://doi. org/10.1046/j.1365-2672.94.s1.5.x.

INSTITUTO SOCIOAMBIENTAL (ISA). Vozes do Xingu: coletânea de artigos para o Dossiê Belo Monte. São Paulo: Instituto Socioambiental, 2015.

JUAREZ, Rodson William Barroso. Mineração em Pedra Branca do Amapari (AP) e os aspectos do pós-fordismo na produção do espaço urbano. 2015. 146 f. Dissertação (Mestrado em Desenvolvimento Social) - Universidade Federal o Amapá, Macapá, 2015.

KATSURAGAWA, Tony Hiroshi; CUNHA, Roberto Penna de Almeida; SOUZA, Daniele Cristina Apoluceno de; GIL, Luiz Herman Soares; CRUZ, Rafael Bastos; SILVA, Alexandre de Almeida e; TADA, Mauro Shugiro; SILVA, Luiz Hildebrando Pereira da. Malária e aspectos hematológicos em moradores da área de influência dos futuros reservatórios das hidrelétricas de Santo Antônio e Jirau, Rondônia, Brasil. Cadernos de Saúde Pública, Rio de Janeiro, v. 25, n. 7, p. 1486-1492, jul. 2009. DOI: http://dx.doi.org/10.1590/S0102-311X2009000700006.

KOIFMAN, Sergio. Geração e transmissão da energia elétrica: impacto sobre os povos indígenas no Brasil. Cadernos de Saúde Pública, Rio de Janeiro, v. 17, n. 2, p. 413-423, mar.-abr. 2001. DOI: http://dx.doi. org/10.1590/S0102-311X2001000200016.

KOPENAWA, Davi; ALBERT, Bruce. A queda do céu: palavras de um xamã yanomami. São Paulo: Companhia das Letras, 2015.

LIMA, André. SiNUCa de bico: mineração em Unidade de Conservação. In: RICARDO, Fany; ROLLA, Alicia (Org.). Mineração em Unidades de Conservação na Amazônia brasileira. São Paulo: Instituto Socioambiental, 2006. p. 9-18.

MARTINS, F. D.; MENDONÇA, M. V. Floresta Nacional de Carajás: compatibilizando a mineração com a conservação. In: BENSUSAN, Nurit; PRATES, Ana Paula (Org.). A diversidade cabe na unidade? Áreas protegidas no Brasil. Brasília: IEB, 2014. p. 25-29.

MINÉRIO de ferro: MMX mostra seu plano de produção. Brasil Mineral Online, São Paulo, n. 271, 20 set. 2006.

MONTEIRO, Maurílio de Abreu. Meio século de mineração industrial na Amazônia e suas implicações para o desenvolvimento regional. Estudos Avançados, São Paulo, v. 19, n. 53, p. 187-207, jan.-abr. 2005. DOI: http://dx.doi.org/10.1590/S0103-40142005000100012.
MORENO, Eduardo Stramandinoli; CABRAL, Joana Oliveira; FREIRE, Maira Posteraro; COSTA, Aline da Silva; COSTA, Tiago da Silva; SOUTO, Raimundo Nonato Picanço; CASTRO, Isai Jorge; NASCIMENTO, Luis Otavio Cordeiro; ZANINI, Volmir; SHIMABUKURO, Paloma Helena Fernandes. Abordagens alternativas para a vigilância da leishmaniose tegumentar em áreas indígenas estudo de caso entre os Wajãpi do Amapá. Vigilância Sanitária Debate: Sociedade, Ciência e Tecnologia, Rio de Janeiro, v. 4, n. 4, p. 51-59, trim. 2016. DOI: https://dx.doi.org/10.22239/2317-269x.00809.

MOURÃO, Fábio Rodrigo Paixão. Evolução da malária na Amazônia oriental na perspectiva das mudanças climáticas globais. 2013. 86 f. Tese (Doutorado em Biodiversidade Tropical) - Universidade Federal do Amapá, Macapá, 2013.

OLIVEIRA, Frederico Fonseca Galvão de; MEDEIROS, Wendson Dantas de Araújo. Bases teórico-conceituais de métodos para avaliação de impactos ambientais em EIA/RIMA. Mercator, Fortaleza, v. 6, n. 11, p. 79-92, jan.-jun. 2007.

OLIVEIRA, Marcelo José de; MATHIS, Armin. O recente ciclo de mineração no estado do Amapá: uma análise preliminar com base na produção mineral, arrecadação de Royalties e taxa anual por hectare. Papers do NAEA, Belém, n. 363, p. 1-29, mar. 2017.

OLIVEIRA, Marcelo José de (Coord.). Diagnóstico do setor mineral do estado do Amapá. Macapá: IEPA, 2010.

OLIVEIRA, Valéria Regina Salla de. Impactos cumulativos na avaliação de impactos ambientais: fundamentação, metodologia, legislação, análise de experiências e formas de abordagem. 2008. $181 \mathrm{f}$. Dissertação (Mestrado em Engenharia Urbana) - Universidade Federal de São Carlos, São Carlos, 2008.

OLSON, Sarah H.; GANGNON, Ronald; ELGUERO, Eric; DURIEUX, Laurent; GUÉGAN, Jean-Frannald; FOLEY, Jonathan A.; PATZ, Jonathan A. Links between climate, malaria, and wetlands in the Amazon Basin. Emerging Infectious Diseases, Bethesda, v. 15, n. 4, p. 659, Apr. 2009. DOI: http://dx.doi.org/10.3201/ eid1504.080822.

PANTOJA, Giselly Marilia Thalez; ANDRADE, Rosemary Ferreira de. Impactos socioambientais decorrentes dos projetos hidrelétricos na bacia do rio Araguari: do aumento populacional à disseminação da malária. Planeta Amazônia: Revista Internacional de Direito Ambiental e Políticas Públicas, Macapá, n. 4, p. 61-74, anual 2012.

PARAÍSO, Luciana Braga. Dilemas da participação na gestão de unidades de conservação: a experiência do projeto Doces Matas na RPPN Mata do Sossego. In: ZHOURI, Andréa; LASCHEFSKI, Klemens; PEREIRA, Doralice Barros (Org.). A insustentável leveza da política ambiental: desenvolvimento e conflitos socioambientais. Belo Horizonte: Autêntica, 2005. (Coleção Sociedade e Meio Ambiente).

PERUZZO, Pedro Pulzatto. Direito à consulta prévia aos povos indígenas no Brasil. Revista Direito e Práxis, Rio de Janeiro, v. 8, n. 4, p. 2708-2740, out.-dez. 2017. DOI: http://dx.doi.org/10.1590/2179$8966 / 2017 / 24631$.

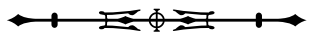


PORTO, Marcelo Firpo; PACHECO, Tania; LEROY, Jean Pierre (Org.). Injustiça ambiental e saúde no Brasil: o mapa de conflitos. Rio de Janeiro: Editora Fiocruz, 2013.

QUINTERO, Lisardo Osorio; DUTARY THATCHER, Bedsy; TADEI, Wanderli Pedro. Biologia de anofelinos amazônicos. XXI. Ocorrência de espécies de Anopheles e outros culicídeos na área de influência da Hidrelétrica de Balbina - cinco anos após o enchimento do reservatório. Acta Amazonica, Manaus, v. 26, n. 4, p. 281-296, dez. 1996. DOI: http://dx.doi.org/10.1590/180943921996264296.

RAMOS, Alcida Rita. O papel político das epidemias: o caso Yanomami. Série Antropologia, Brasília, n. 153, p. 1-21, 1993.

REZENDE, Helder Ricas; SESSA, Paulo Augusto; FERREIRA, Adelson Luiz; SANTOS, Claudiney Biral dos; LEITE, Gustavo Rocha; FALQUETO, Aloísio. Efeitos da implantação da Usina Hidrelétrica de Rosal, rio Itabapoana, estados do Espírito Santo e Rio de Janeiro, sobre anofelinos, planorbídeos e flebotomíneos. Revista da Sociedade Brasileira de Medicina Tropical, Uberaba, v. 42, n. 2, p. 160-164, mar.-abr. 2009. DOI: http://dx.doi. org/10.1590/S0037-86822009000200013.

RIGOTTO, Raquel Maria. Inserção da saúde nos estudos de impacto ambiental: o caso de uma termelétrica a carvão mineral no Ceará. Ciência e Saúde Coletiva, Rio de Janeiro, v. 14, n. 6 , p. 2049-2059, dez. 2009. DOI: http://dx.doi.org/10.1590/S141381232009000600012.

SANTIAGO, Abinoan. Mineradora anuncia ter encontrado ouro de alto teor em cidade do Amapá. G1-Amapá, 23 jun. 2016. Disponível em: <http://g1.globo.com/ap/amapa/noticia/2016/06/ mineradora-anuncia-ter-encontrado-ouro-de-alto-teor-emcidade-do-amapa.html>. Acesso em: 20 jul. 2016.

SEBBEN, Marina; DA SILVA, Elcio Domingues. Licenciamento ambiental e o retrocesso da PEC 65 de 2012 para a proteção do meio ambiente e da sociedade. Revista Aporia Jurídica, Ponta Grossa, v. 1, n. 6, p. 388-410, jul.-dez. 2016.

SILVA, Arthur Cardoso. Mineração e unidades de conservação no Amapá: possibilidades e riscos. 2014. 48 f. Monografia (Bacharelado em Ciências Ambientais) - Universidade Federal do Amapá, Macapá, 2014.

SILVA, Christian Nunes da; LIMA, Ricardo Ângelo Pereira de; SILVA, João Marcio Palheta da. Uso do território e impactos das construções de hidroelétricas na bacia do rio Araguari (AmapáBrasil). PRACS: Revista Eletrônica de Humanidades do Curso de Ciências Sociais da UNIFAP, Macapá, v. 9, n. 2, p. 123-140, jul.-dez. 2016. DOI: http://dx.doi.org/10.18468/pracs.2016v9n2. p123-140.
SILVEIRA, Missifany; ARAÚJO NETO, Mário Diniz de. Licenciamento ambiental de grandes empreendimentos: conexão possível entre saúde e meio ambiente. Ciência e Saúde Coletiva, Rio de Janeiro, v. 19, n. 9, p. 3829-3838, set. 2014. DOI: http://dx.doi. org/10.1590/1413-81232014199.20062013.

SILVEIRA, Missifany; PADILHA, José Braz Damas; SCHNEIDER, Mariana; AMARAL, Pablo Sebastian Tavares; CARMO, Thenille Faria Machado do; FRANCO-NETO, Guilherme; ROHLFS, Daniela Buosi. Perspectiva da avaliação de impacto à saúde nos projetos de desenvolvimento no Brasil: importância estratégica para a sustentabilidade. Caderno de Saúde Coletiva, Rio de Janeiro, v. 20, n. 1, p. 57-63, trim. 2012.

VASCONCELOS, Cíntia Honório; NOVO, Evlyn Márcia Leão de Moraes; DONALISIO, Maria Rita. Uso do sensoriamento remoto para estudar a influência de alterações ambientais na distribuição da malária na Amazônia brasileira. Cadernos de Saúde Pública, Rio de Janeiro, v. 22, n. 3, p. 517-526, mar. 2006. DOI: http:// dx.doi.org/10.1590/S0102-311X2006000300006.

VILHENA, Marlene dos Santos. A responsabilidade socioambiental das empresas mineradoras instaladas nos municípios de Pedra Branca do Amapari e Serra do Navio no Amapá: reflexão sobre a atividade mineradora e as práticas ambientais sustentáveis. 2014. 141 f. Dissertação (Mestrado em Direitos Difusos e Coletivos) Pontifícia Universidade Católica de São Paulo, São Paulo, 2014.

WANDERLEY, Luiz Jardim de Moraes. Conflitos e movimentos sociais populares em área de mineração na Amazônia brasileira. 2008. 166 f. Dissertação (Mestrado em Geografia) - Universidade Federal do Rio de Janeiro, Rio de Janeiro, 2008.

WILSON, Edward O. Consilience: the unity of knowledge. New York: Alfred A. Knopf, 1998.

ZHOURI, Andréa; VALENCIO, Norma; OLIVEIRA, Raquel; ZUCARELLI, Marcos; LASCHEFSKI, Klemens; SANTOS, Ana Paula. O desastre da Samarco e a política das afetações: classificações e ações que produzem o sofrimento social. Ciência e Cultura, São Paulo, v. 68, n. 3, p. 36-40, set. 2016. DOI: http:// dx.doi.org/10.21800/2317-66602016000300012.

ZHOURI, Andréa. Justiça ambiental, diversidade cultural e accountability: desafios para a governança ambiental. Revista Brasileira de Ciências Sociais, São Paulo, v. 23, n. 68, p. 97-107, out. 2008. DOI: http://dx.doi.org/10.1590/S010269092008000300007

ZHOURI, Andréa; LASCHEFSKI, Klemens; PEREIRA, Doralice Barros (Org.). A insustentável leveza da política ambiental: desenvolvimento e conflitos socioambientais. Belo Horizonte: Autêntica, 2005. (Coleção Sociedade e Meio Ambiente).

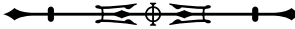

